\title{
Lessons Learned from the 2011 Great East Japan Tsunami: Performance of Tsunami Countermeasures, Coastal Buildings, and Tsunami Evacuation in Japan
}

\author{
Anawat Suppasri, ${ }^{1}$ Nobuo Shuto, ${ }^{1}$ Fuminiko Imamura, ${ }^{1}$ Shunichi Koshimura, ${ }^{1}$ Erick Mas, ${ }^{1}$ \\ and Ahmet Cendet Yalciner ${ }^{2}$
}

Abstract-In 2011, Japan was hit by a tsunami that was generated by the greatest earthquake in its history. The first tsunami warning was announced $3 \mathrm{~min}$ after the earthquake, as is normal, but failed to estimate the actual tsunami height. Most of the structural countermeasures were not designed for the huge tsunami that was generated by the magnitude $M=9.0$ earthquake; as a result, many were destroyed and did not stop the tsunami. These structures included breakwaters, seawalls, water gates, and control forests. In this paper we discuss the performance of these countermeasures, and the mechanisms by which they were damaged; we also discuss damage to residential houses, commercial and public buildings, and evacuation buildings. Some topics regarding tsunami awareness and mitigation are discussed. The failures of structural defenses are a reminder that structural (hard) measures alone were not sufficient to protect people and buildings from a major disaster such as this. These defenses might be able to reduce the impact but should be designed so that they can survive even if the tsunami flows over them. Coastal residents should also understand the function and limit of the hard measures. For this purpose, nonstructural (soft) measures, for example experience and awareness, are very important for promoting rapid evacuation in the event of a tsunami. An adequate communication system for tsunami warning messages and more evacuation shelters with evacuation routes in good condition might support a safe evacuation process. The combination of both hard and soft measures is very important for reducing the loss caused by a major tsunami. This tsunami has taught us that natural disasters can occur repeatedly and that their scale is sometimes larger than expected.

Key words: The 2011 East Japan earthquake and tsunami, tsunami countermeasures, Sanriku coast, Sendai plain.

1 International Research Institute of Disaster Science, Tohoku University, Sendai, Japan. E-mail: suppasri@irides.tohoku. ac.jp; shuto.nobuo@gmail.com; imamura@irides.tohoku.ac.jp; koshimura@irides.tohoku.ac.jp; erick@tsunami2.civil.tohoku.ac. jp;

2 Department of Civil Engineering, Ocean Engineering Research Center, Middle East Technical University, Ankara, Turkey. E-mail: yalciner@metu.edu.tr

\section{Introduction}

On 11 March 2011, a strong earthquake of magnitude $M=9.0$ (JMA, 2011) occurred in East Japan, generating a devastating tsunami. No one was expecting an earthquake of this magnitude in Japan. Japan is well known as a leading tsunami disaster prevention country, because it has countermeasures and evacuation plans set in place. Along the Sanriku ria coast, where V-shape coastlines can cause a tsunami wave to accumulate inside the bay, tsunamis can easily be amplified to heights exceeding $10 \mathrm{~m}$. Therefore, many structural and non-structural tsunami countermeasures were constructed along the Sanriku coast (Aве and Imamura, 2010). Nevertheless, the $600 \mathrm{~km}$ Sanriku coast, which extends northwards from Sendai and covers the Miyagi, Iwate, and Aomori prefectures, was heavily damaged by the 2011 tsunami. Some of the damage was observed during primary damage field surveys in Miyagi (SUPPASRI et al., 2012a) and Iwate prefectures (YALCINER et al., 2012). In this paper, the effectiveness of these countermeasures during the 2011 tsunami, and the mechanisms by which they were damaged, are discussed briefly; examples of breakwaters in Kamaishi and Ofunato; tsunami gates in Fudai and MinamiSanriku; seawalls in Taro, Yamada, and Ishinomaki; and control forests in Rikuzentakata and Natori are discussed. The damage to houses in relation to the materials that were used and number of stories is also discussed; overturned reinforced concrete buildings in Onagawa are presented as examples. Similar to the lessons learned from the 2004 Indian Ocean tsunami (SANTOS et al., 2007; SuPPASRi et al., 2012c), the lessons learned from this tsunami, including those regarding the effects of the tsunami on a highland 
residence in Toni-Hongo, the Namiwake shrine in Sendai, and damage data from historical tsunamis in the Sanriku area, are discussed. Examples of successful evacuations, for example the "Miracles of Kamaishi" and "Inamura no Hi", the tsunami festival in the Wakayama province are provided.

\section{Historical Tsunamis that have Affected the Sanriku Coast and Sendai Plain Areas}

The Sanriku coast is often hit by giant tsunamis. If we limit our discussion to tsunamis generated by earthquakes over M8.0, the first historical tsunami is the Jogan tsunami in 869 , followed by the KeichoSanriku tsunami in 1611, the Meiji-Sanriku tsunami in 1896, the Showa-Sanriku tsunami in 1933, the farfield tsunami from Chile in 1960, and the Great East Japan tsunami in 2011 (Fig. 1; Table 1). The 1896 tsunami caused nearly 22,000 deaths (YamashitA, 2008a), the highest number of deaths caused by a tsunami in Japanese history. In fact, large earthquakes such as that which generated the Jogan-type tsunami occurs, on average, every 800-1,100 years (MinOuRA et al., 2001). More than 1,100 years have passed since the Jogan tsunami, so there was a high probability that a large earthquake and tsunami would occur. However, with only one historical record of the Jogan tsunami and the limited Jogan tsunami deposit areas (mainly in Sendai and Ishinomaki plains), information about the magnitude of this earthquake and the probability of another Jogan event required additional support data and verification.

Before the 2011 event, there was a $99 \%$ probability that another $M=7.5-8.0$ earthquake would occur off of the Miyagi Prefecture within the next 30 years (Table 2) (SEndai CiTy, 2010). A series of M7.4-M8.0 earthquakes have occurred in the Miyagi Sea since 1793, and the average time between them is 37 years (Sendai city, 2010). Many countermeasures have been constructed in preparation for these tsunamis, which are predicted to damage the Sanriku coast and the Sendai plain.

The Sendai plain is a low-hazard area compared with the Sanriku coast. Historical records show there have been no large tsunami events in the Sendai plain area since the 1611 Keicho-Sanriku tsunami, whereas the Sanriku coast was affected by great tsunamis in
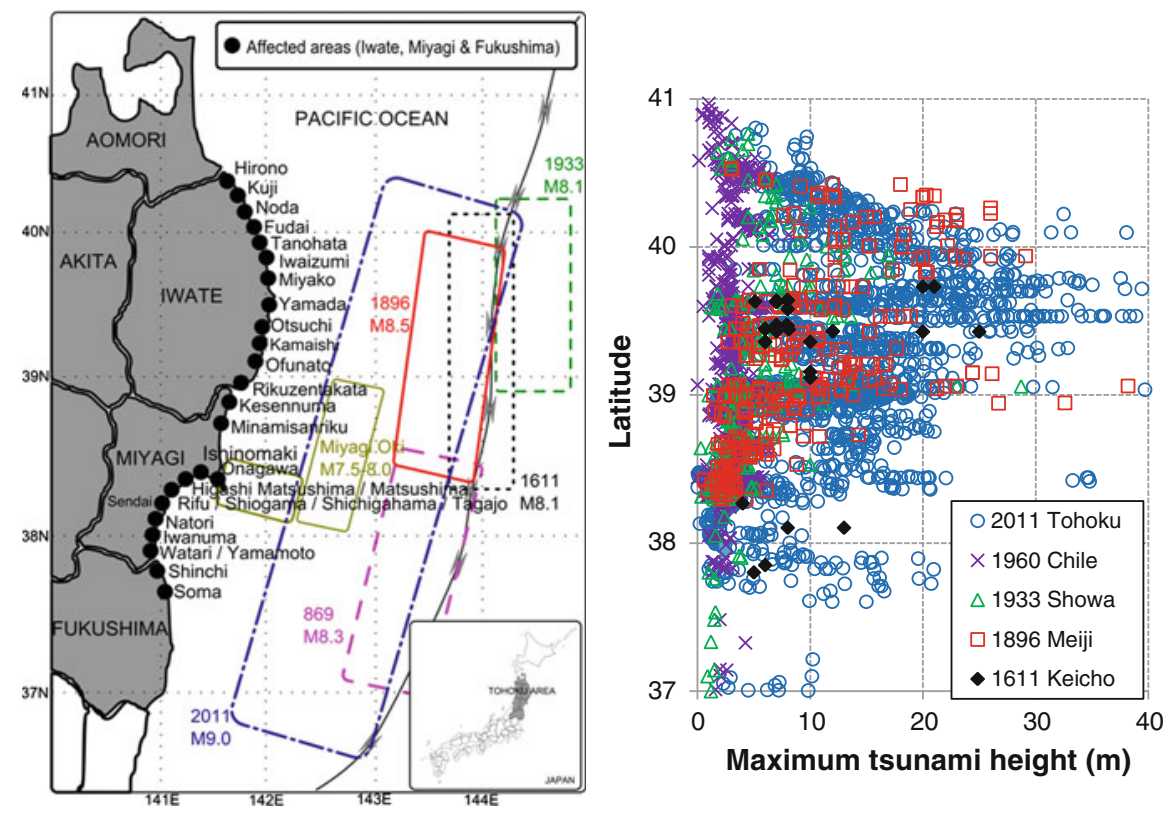

Figure 1

Historical tsunamis in the Sanriku area, the areas that were affected by the 2011 Tohoku tsunami, and the maximum tsunami height of historical tsunamis 
Table 1

Historical tsunamis in the Sanriku area and the damage which resulted

\begin{tabular}{|c|c|c|c|c|}
\hline $\mathrm{DD} / \mathrm{MM} / \mathrm{YY}$ & Name & $\begin{array}{l}\text { Earthquake } \\
\text { magnitude }\end{array}$ & Damage & $\begin{array}{l}\text { Maximum tsunami } \\
\text { height }(\mathrm{m}) / \text { location }\end{array}$ \\
\hline 9 July 869 & Jogan & $>8.3$ & More than 1,000 deaths & \\
\hline 2 Dec 1611 & Keicho Sanriku & $>8.1$ & More than 5,000 deaths & \\
\hline 15 June 1896 & Meiji Sanriku & 8.5 & $\begin{array}{l}21,959 \text { deaths and more than } \\
10,000 \text { houses destroyed }\end{array}$ & $38.2 /$ Ryori area, Ofunato city \\
\hline 3 Mar 1933 & Showa Sanriku & 8.1 & $\begin{array}{l}3,064 \text { deaths and } 1,810 \text { houses } \\
\text { destroyed }\end{array}$ & $28.7 /$ Ryori area, Ofunato city \\
\hline 22 May 1960 & Great Chilean & 9.5 & $\begin{array}{l}142 \text { (in Japan) and 1,625 houses } \\
\text { destroyed }\end{array}$ & 22 May 1960 \\
\hline 11 Mar 2011 & Great East Japan & 9.0 & $\begin{array}{c}19,000 \text { deaths and more than } 836,500 \\
\text { houses damaged and destroyed }\end{array}$ & $\begin{array}{l}\text { 40.5/Omoe-Aneyoshi area, } \\
\text { Miyako city }\end{array}$ \\
\hline
\end{tabular}

Table 2

Records of earthquakes in the Miyagi Sea

\begin{tabular}{llll}
\hline DD/MM/YY & \multicolumn{2}{l}{ Lag time } & Magnitude \\
\hline 17 Feb 1793 & & 8.2 \\
20 July 1835 & 42.4 years & 37.1 years on & 7.3 \\
21 Oct 1861 & 26.3 years & average & 7.4 \\
20 Feb 1897 & 35.3 years & 7.4 \\
3 Nov 1936 & 39.7 years & 7.4 \\
12 June 1978 & 41.6 years & 7.4 \\
Before 11 Mar 2011 & 33 years had passed, & $7.5-8.0$ \\
& so the possibility of \\
& occurrence was 99 \% \\
\hline
\end{tabular}

1896, 1933, and 1960 (Fig. 1). The primary concern is for the ria coast, with its remarkable tsunamiamplification property because of its narrow, $\mathrm{V}$-shaped topography, rather than the plain coast. In addition, because of the location of the earthquakes in 1896 and 1933, which occurred in the north, the Sendai plain was protected from these tsunamis because it is located inside a bay behind the Sanriku coast (Fig. 2). For instance, in Ofunato, maximum runup heights of 38.2 and $28.7 \mathrm{~m}$ were recorded for the 1896 Meiji and 1933 Showa tsunamis, respectively. However, for these two tsunamis, maximum runup heights of less than 5 and $3.9 \mathrm{~m}$, respectively (Fig. 1), were recorded in the Sendai plain (SAwAI et al., 2008; Yamashita 2008a, b). The tsunami in 1960 that was generated by the great earthquake in Chile also concentrated in, and mainly damaged, the Sanriku areas. However, the 2011 tsunami was generated by a large earthquake, and its $500 \mathrm{~km}$ rupture covered the whole area of the Tohoku region.

\section{Tsunami Countermeasures}

\subsection{Tsunami Breakwaters}

Large-scale tsunami breakwaters are present along the Sanriku coast. They were constructed to protect cities from future tsunamis, because of the region's long history of devastating tsunamis. The tsunami breakwaters were designed to resist tsunamis that are similar in strength to the 1896 Meiji Sanriku tsunami. Two well-known tsunami breakwaters are located in Kamaishi city and Ofunato city. In Kamaishi, the tsunami breakwaters were constructed at the entrance to the bay; they are $63 \mathrm{~m}$ deep and hold the Guinness world record for the deepest breakwaters (Fig. 3, left). Construction of the breakwaters was completed in 2009; they have a $300 \mathrm{~m}$ opening and are 670 and $990 \mathrm{~m}$ long (KAMAISHI PORT OFFICE, 2011). The two tsunami breakwaters in Ofunato city were constructed after the city was struck by a large tsunami with long-period waves caused by resonance with the tsunami generated by the 1960 Chilean earthquake (Fig. 3, right). The two breakwaters are located at the bay entrance where the water is $38 \mathrm{~m}$ deep; they have a $200 \mathrm{~m}$ wide opening and are 290 and $250 \mathrm{~m}$ long (KAMAISHI PORT OFFICE, 2011). Construction of the breakwaters was completed in 1967 and successfully protected the city from the Tokachi-oki tsunami in 1968.

However, the 2011 Tohoku tsunami was higher than the designers expected. The tsunami caused major damage to the breakwaters and inundated both cities. Nevertheless, the breakwaters helped to reduce 

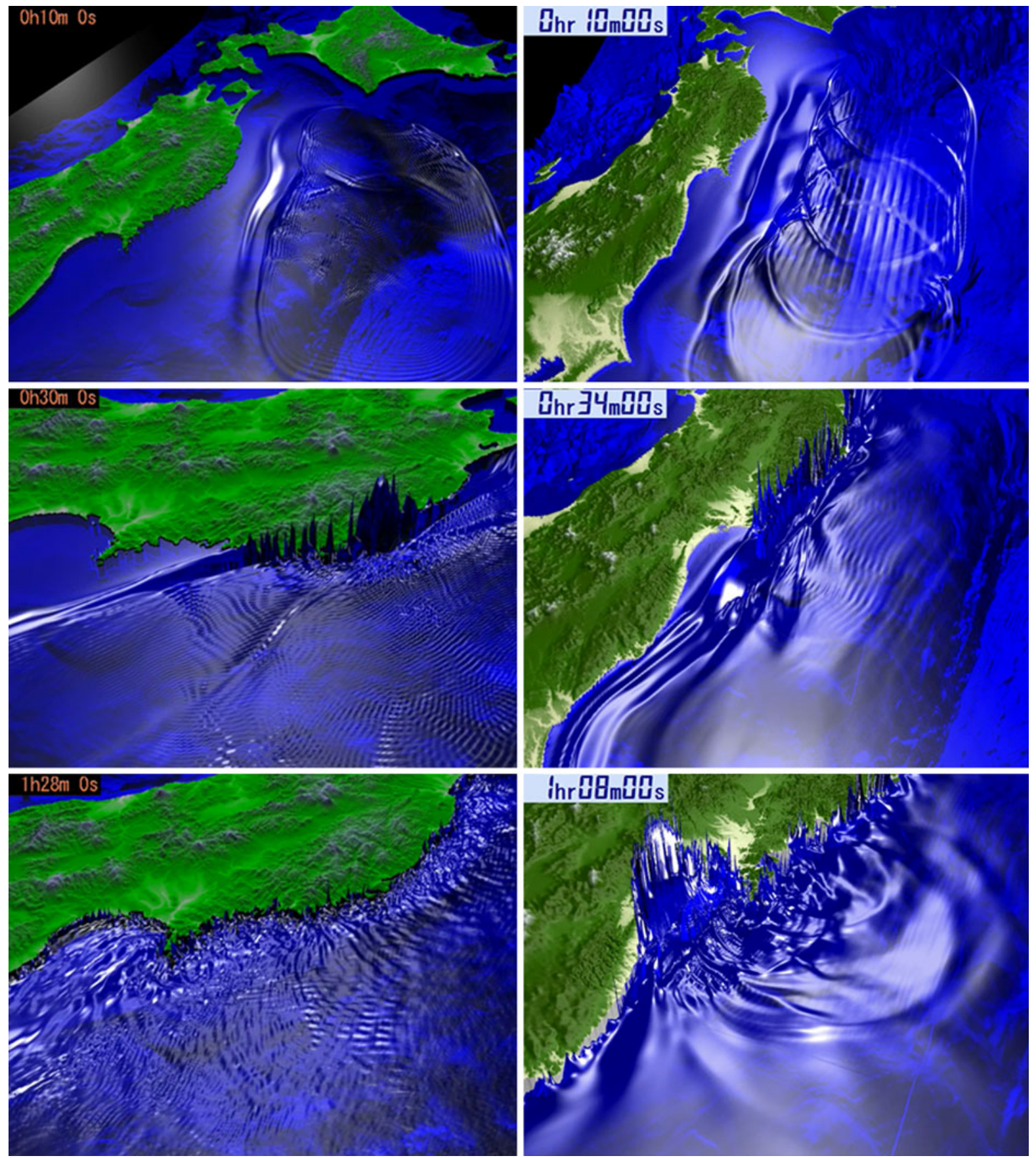

Figure 2

Comparison of the propagation patterns of the 1896 Meiji-Sanriku tsunami and the 2011 Great East Japan tsunami after 10, 30, and 60 min

the impact of the tsunami (both tsunami height and arrival time) on the cities, especially Kamaishi, where many houses still remain (Fig. 4). Figures 5 and 6 show the performance of the Kamaishi breakwaters and the mechanisms by which they were damaged (PARI, 2011). The breakwaters were located on a rock foundation. Thirty-meter-wide blocks were arranged on top of the rock foundation along the 

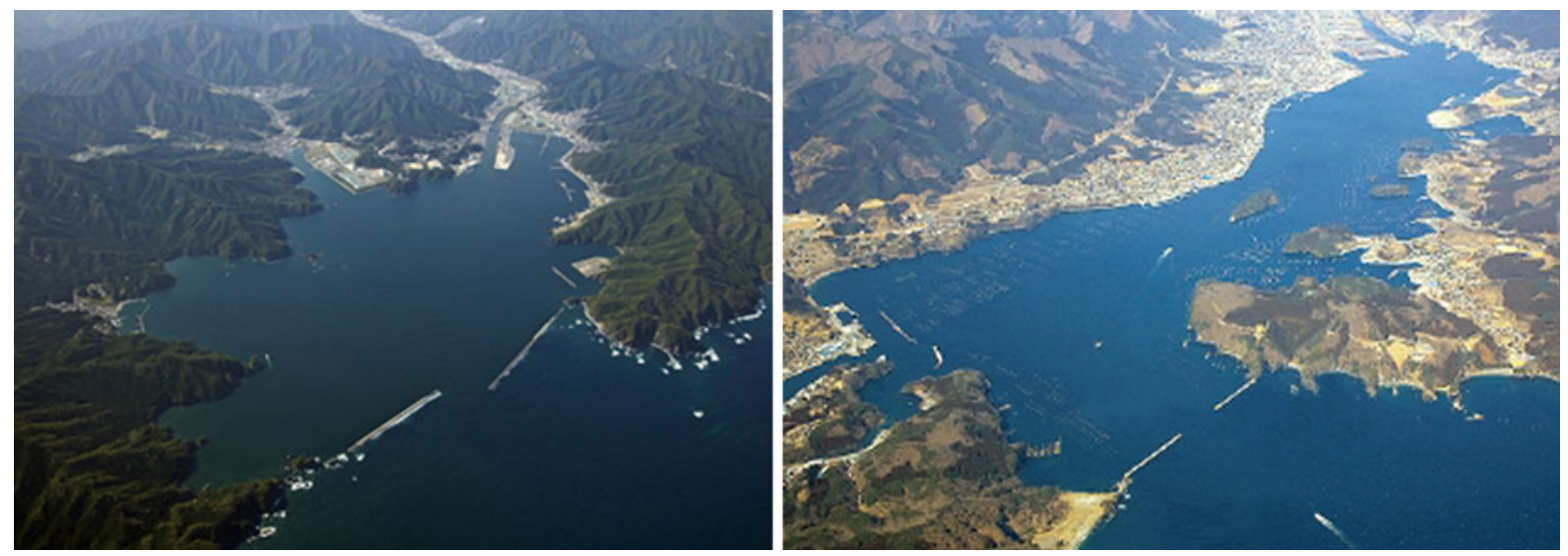

Figure 3

Tsunami breakwaters in Kamaishi city and in Ofunato city (before the 2011 tsunami)

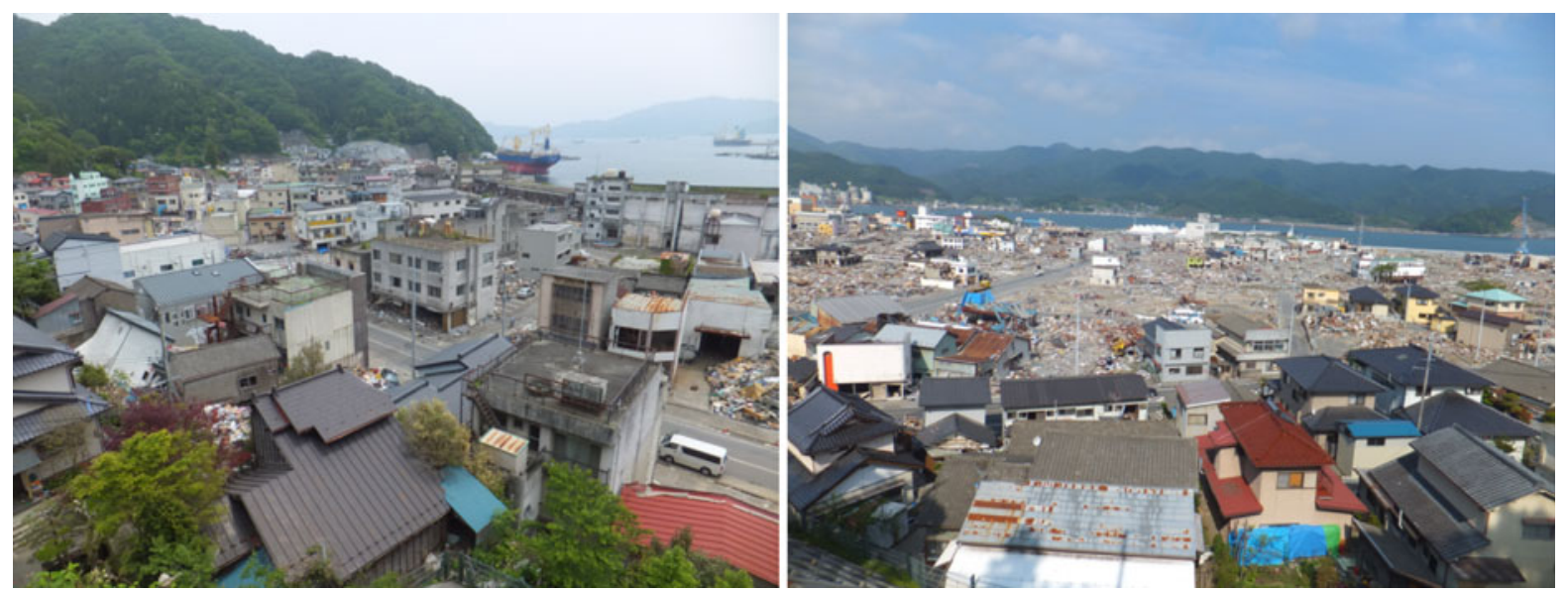

Figure 4

Damage from the tsunami inundation of Kamaishi city with a maximum runup height of $11.7 \mathrm{~m}(1 / 6 / 2011)$ and of Ofunato city with a maximum runup height of $10.9 \mathrm{~m}(1 / 6 / 2011)$

direction of the axis of the breakwaters. The blocks rose $6 \mathrm{~m}$ above sea level and were designed to protect the city from a $5.6 \mathrm{~m}$ high tsunami. A tsunami height of $6.7 \mathrm{~m}$ was measured at a GPS station in Kamaishi Sea. On the basis of these data, two simulations were performed for cases with and without breakwaters (PARI, 2011). From the results, the height (mean sea level, MSL) of the tsunami was $10.8 \mathrm{~m}$ in front of the blocks and $2.6 \mathrm{~m}$ behind the blocks; therefore, the blocks helped to reduce the tsunami height by $8.2 \mathrm{~m}$ (Figs. 5, 6). With regard to inundation by the tsunami, the breakwaters reduced the tsunami height (at the shoreline) from 13.7 to $8.0 \mathrm{~m}$ and reduced the runup height from 20.2 to $10.0 \mathrm{~m}$ (PARI, 2011). Because of the strong current in the $30 \mathrm{~cm}$ spaces between the blocks, the rock foundation was damaged. Eventually, $\sim 70 \%$ of the blocks were destroyed. This process occurred slowly; as a result, the arrival time of the tsunami inundation was delayed by $8 \mathrm{~min}$ (from 28 to $36 \mathrm{~min}$ ) (PARI, 2011). However, the tsunami breakwaters at Ofunato were more seriously damaged and are currently submerged in the sea. Possible reasons are that the Ofunato breakwaters were constructed using earthquake resistance design of nearly $40-50$ years ago and the wave period of the strong tsunami current 


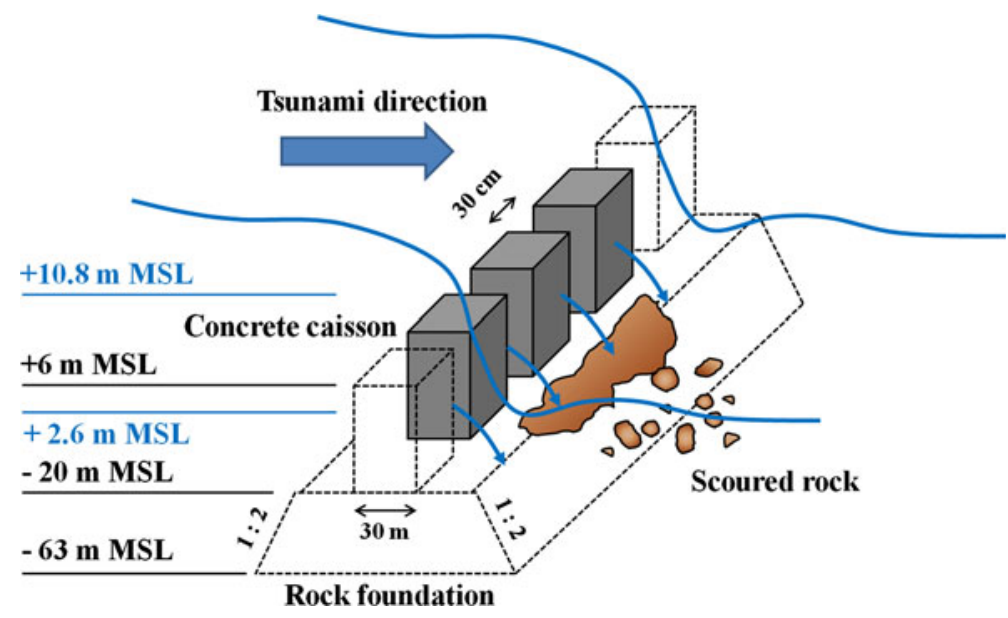

Figure 5

Mechanisms of damage to the Kamaishi breakwaters

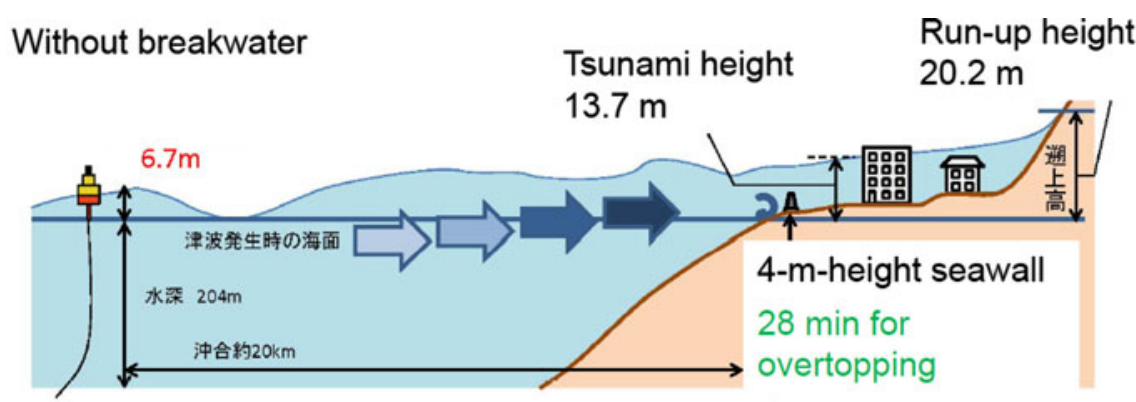

With breakwater

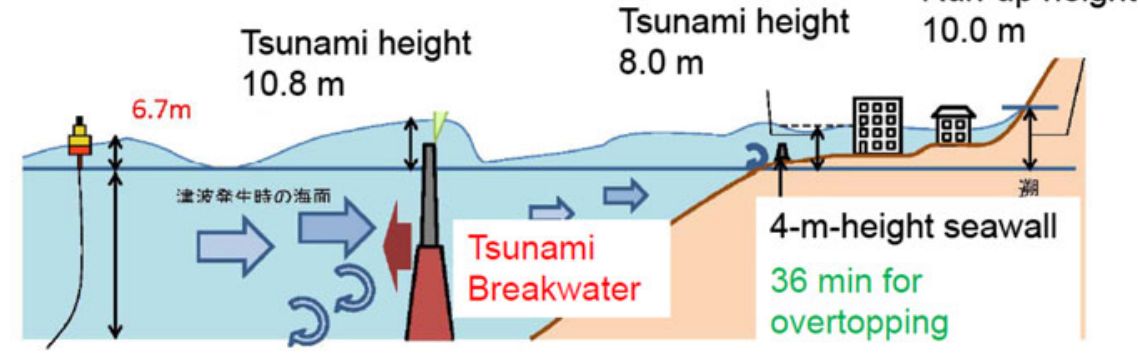

Figure 6

Tsunami impact reduction performance of the Kamaishi breakwaters (PARI, 2011)

might have been nearly the same as the natural period of a wave inside Ofunato bay.

\subsection{Seawalls}

Seawalls are found almost everywhere along the coasts of Japan. According to reports from Ministry of Land, Infrastructure, Transport, and Tourism
(MLIT, 2011), the length of the seawalls damaged and destroyed in Iwate, Miyagi, and Fukushima prefectures is $\sim 190 \mathrm{~km}$ out of a total length of $\sim 300 \mathrm{~km}$. According to the reports, tsunami overflows of $<1 \mathrm{~m}$ caused a relatively small amount of damage but overflows larger than 3-4 m completely destroyed the seawalls because most of them were designed to protect the land from high tides or 

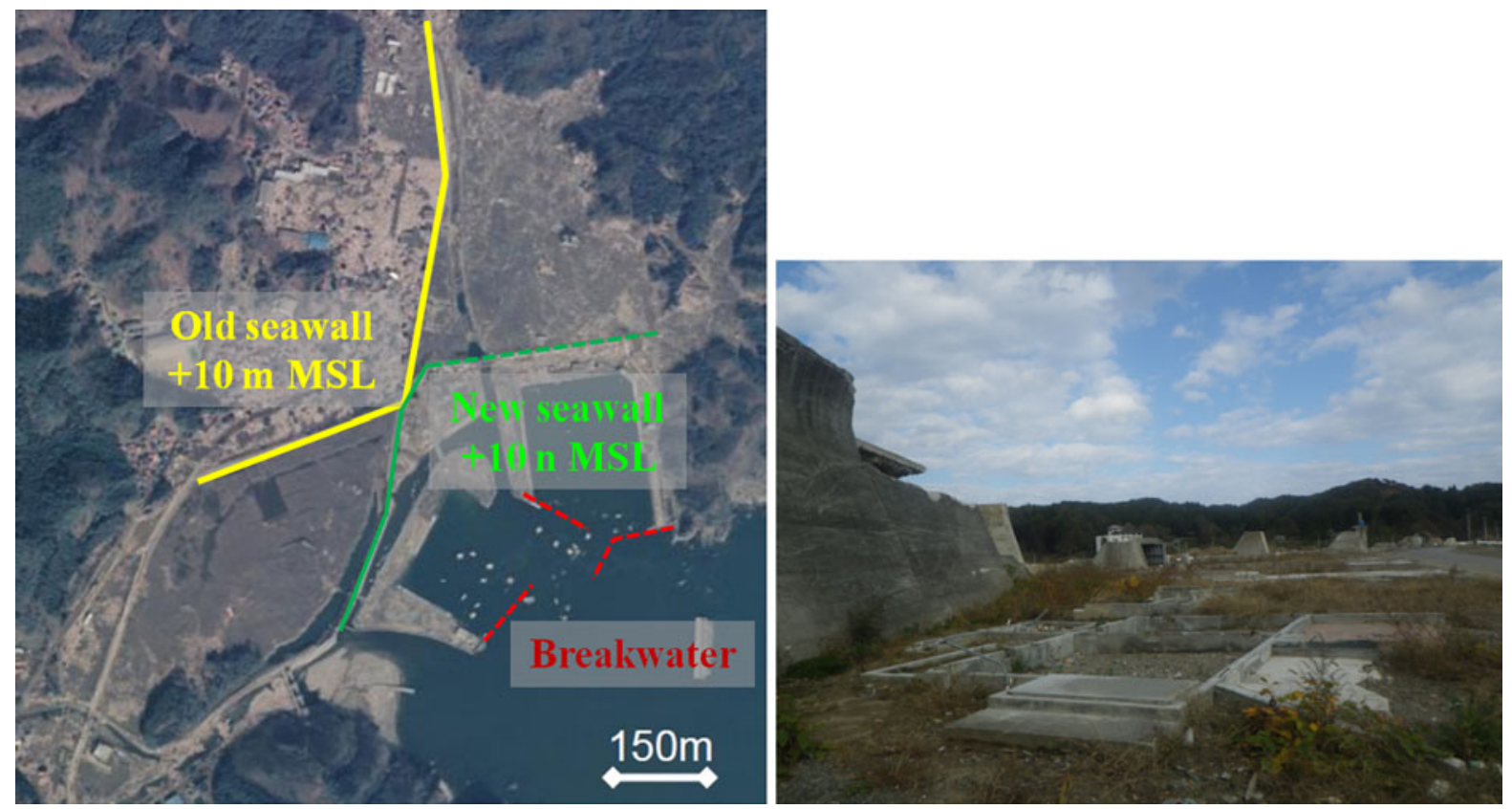

Figure 7

Seawalls in Taro town. Damage occurred to the eastern parts of the new seawalls (9/11/2011)

typhoons. However, some of them, for example the seawall in Taro town, were meant to serve as tsunami barriers. Taro town experienced tsunamis in 1611 , 1896 (a tsunami height of $15 \mathrm{~m}, 83 \%$ fatality, and $100 \%$ of the houses destroyed) and 1933 (a tsunami height of $10 \mathrm{~m}, 32 \%$ fatality, and $63 \%$ of the houses destroyed). In 1934, construction of two, $10 \mathrm{~m}$ high seawalls (measured from the mean seawater level) was started; the purpose of the seawalls was to protect the town by allowing the tsunami to flow along both sides of the seawalls. They were completed in 1958, two years before the 1960 Chile tsunami, and could fully protect the town from a maximum tsunami height of $3.5 \mathrm{~m}$. In the $1970 \mathrm{~s}$, the town constructed another two lines of $10 \mathrm{~m}$ high seawalls to accommodate the increasing population (KAMAISHI PORT OFFICE, 2011). The total length of the seawalls is $\sim 2.4 \mathrm{~km}$, as shown in Fig. 7, left. The designs of both of the seawalls took only the 1933 tsunami into consideration. However, the 2011 tsunami flowed over the two-line seawalls, damaged most houses, with $5 \%$ fatality, and destroyed the eastern part of the new seawall (Fig. 7, right).
There are three main reasons why the seawalls were damaged.

- The two seawalls crossed in an X shape, which caused the tsunami to accumulate and increase in size at the center of the seawalls.

- The foundations of the seawalls were weakened by the river on the eastern side of the town. Soil properties near rivers may have disrupted the stability of foundations.

- The seawalls were not maintained properly and had not been adequately connected to each other. The tsunami flowed over the seawalls and became a high-speed water jet. The strong current at high speed caused scouring around the foundations.

Examples of damage to typical seawalls can be found in Ishinomaki city (Fig. 8, left) and in HigashiMatsushima city. The tsunami height near the control forests of both cities was 7-8 $\mathrm{m}$. On the sea side, the surfaces of the seawalls survived, but on the land side, severe scouring occurred at the foundations. Another example of damaged seawalls is shown in Fig. 8, right. In Yamada town, five blocks of seawalls of total length 

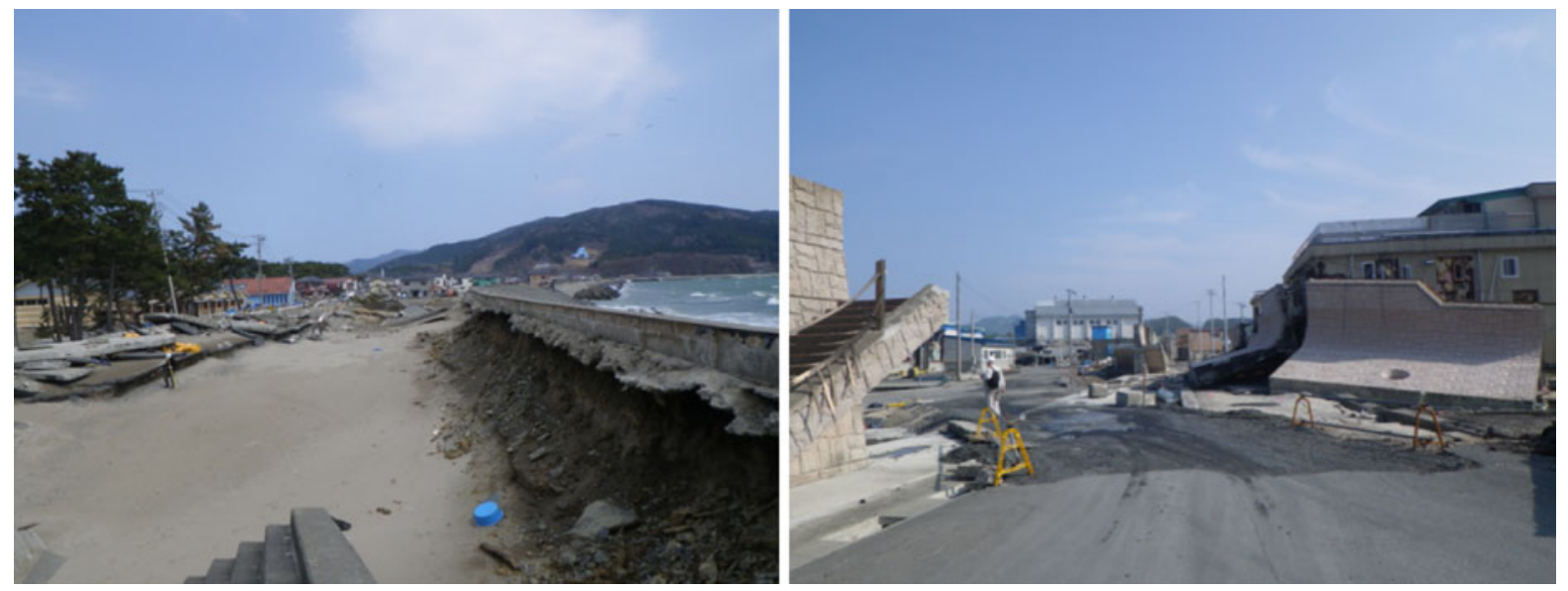

Figure 8

Seawalls damaged by scouring in Ishinomaki city (left, 26/4/2011) and by sliding in Yamada town (right, 31/5/2011)
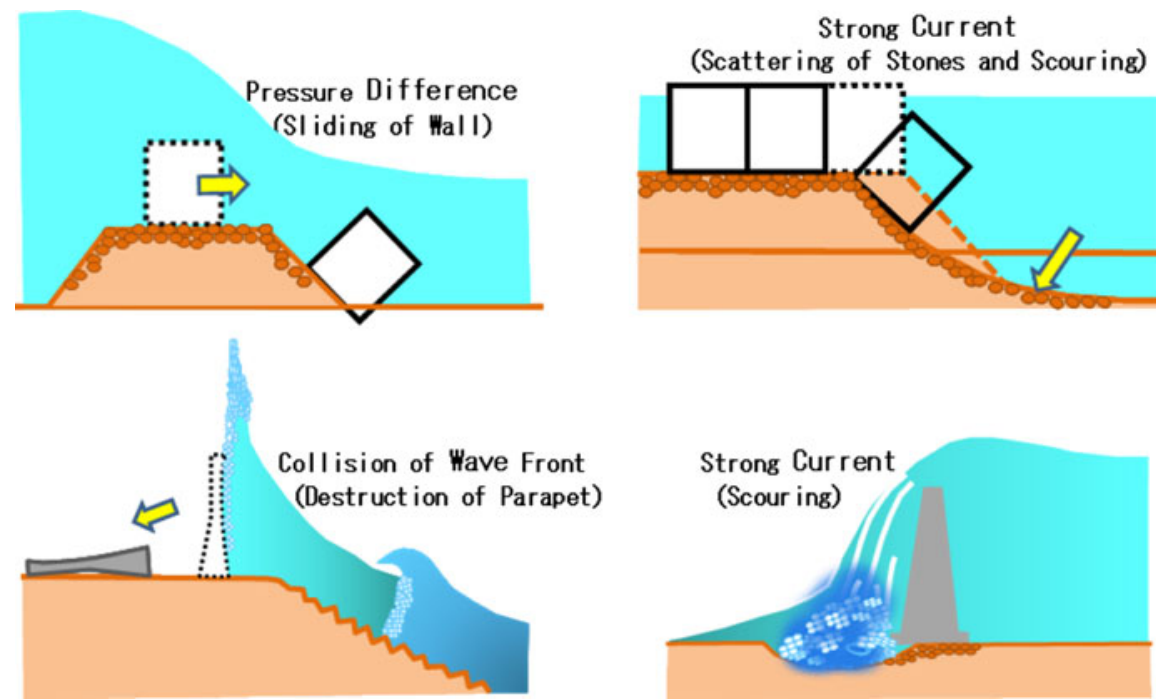

Figure 9

Typical mechanisms of damage to seawalls (PARI, 2011)

of $50 \mathrm{~m}$ were moved by the tsunami. The block structure survived but failed because of poor connection with the foundations and with neighboring blocks. Figure 9 shows typical mechanisms of damage to seawalls including sliding because of the pressure difference, overturning because of collision of the wavefront, and scouring by strong currents (PARI, 2011).

\subsection{Tsunami Gates}

Fudai village developed along the Fudai River. It suffered from the 1896 and 1993 tsunamis that propagated along the river. In 1984, $15.5 \mathrm{~m}$ high tsunami gates were constructed to close the river mouth in case of tsunamis. Fudai was the location of a successful countermeasure structure that protected the village from the 2011 tsunami. The $17 \mathrm{~m}$ high tsunami flowed over the gate but inundated only a few hundred meters past the gate (NIKKEI NEWSPAPER, 2011), as shown in Fig. 10, left. Most of Fudai village, including the evacuation shelters (primary and secondary schools), was protected, as shown in Fig. 10, right, and no loss of human life was reported (ToKen, 2011). If there had not been a tsunami gate, 


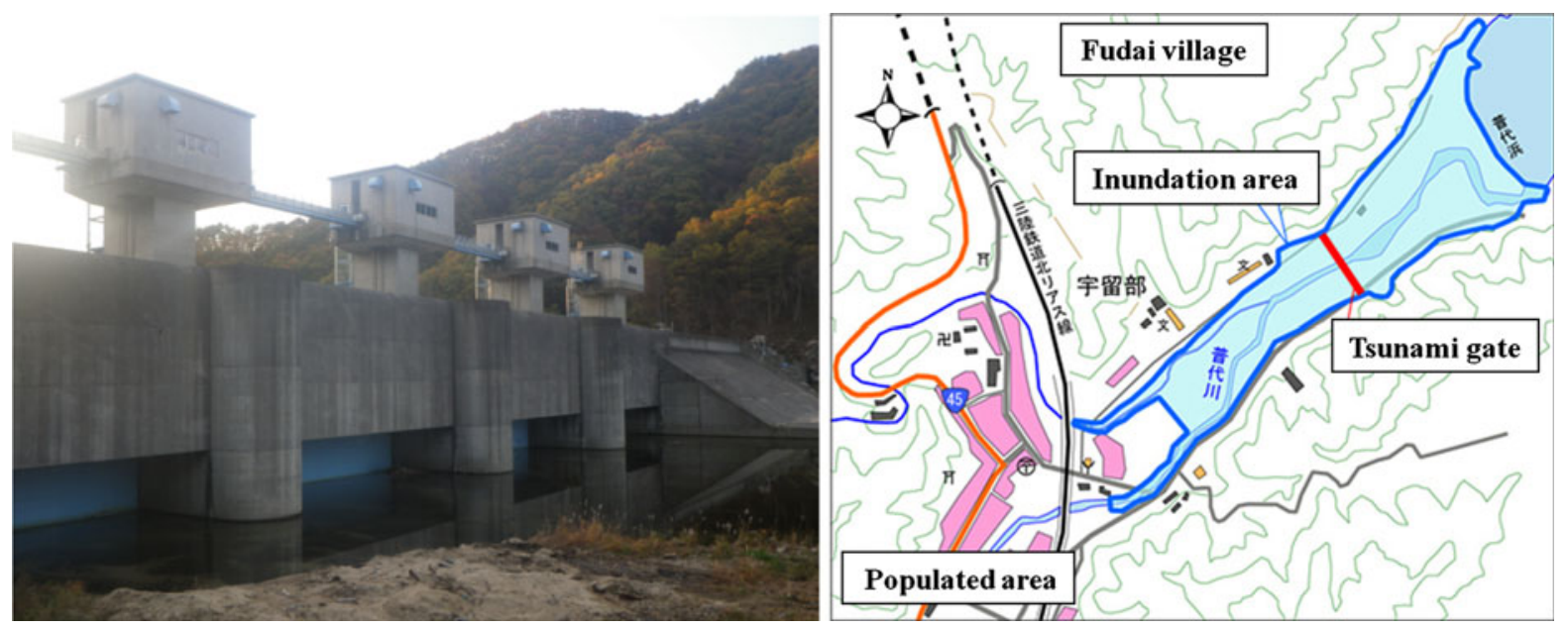

Figure 10

The tsunami gate that protected Fudai village and led to no reported casualties (9/11/2011)
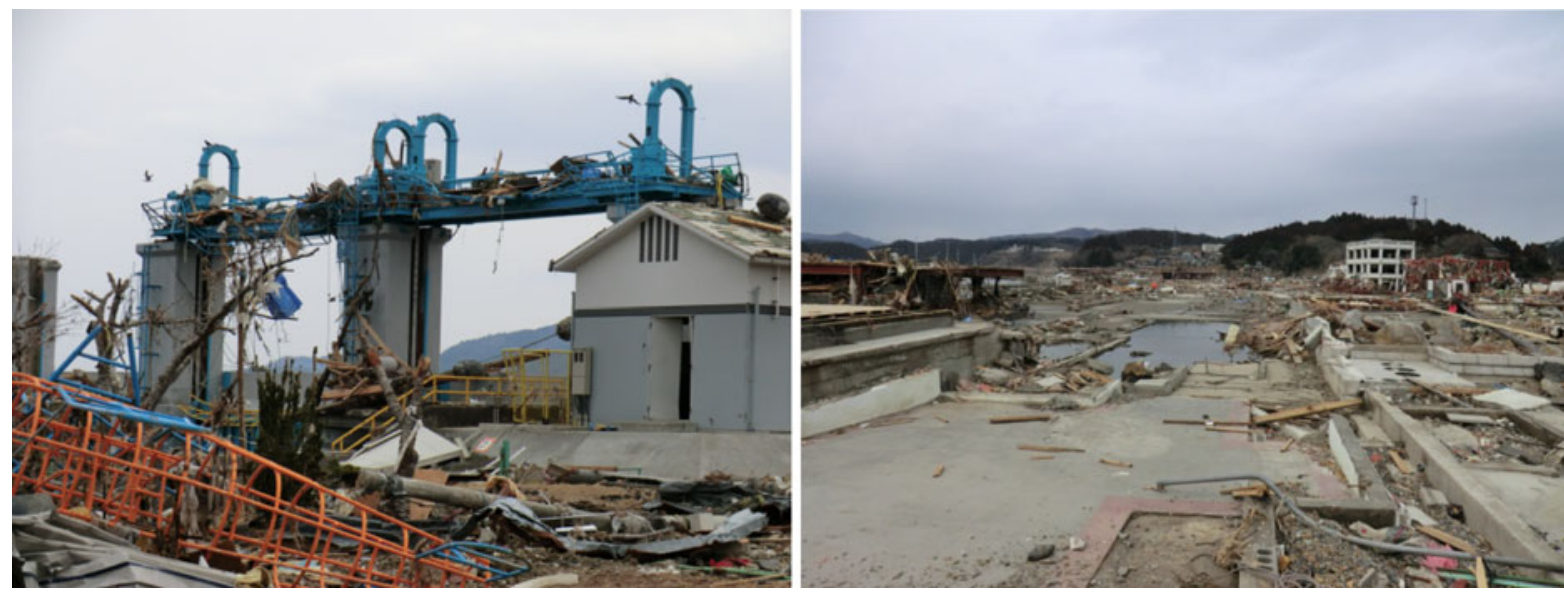

Figure 11

The damaged tsunami gate in Minami-Sanriku town and the town's condition after the tsunami (25/3/2011)

the tsunami would have damaged the center of the village (IWATE PREFECTURE, 2011).

The residents of Minami-Sanriku town have high tsunami awareness because of previous experience with tsunamis. The maximum height of the tsunami in Minami-Sanriku town was $>10 \mathrm{~m}$ in some areas, whereas the average height of past tsunamis was $<5 \mathrm{~m}$. Seawalls and tsunami gates were constructed at $+4.6 \mathrm{~m}$ MSL after the 1960 Chile tsunami (Minami-SanRiku town, 2011) and residents did not expect such a large tsunami, because the first tsunami warning had prediced $3 \mathrm{~m}$ in Miyagi prefecture. Tsunami evacuation drills are conducted every year. However, the tsunami gates and seawalls were overwhelmed and did not stop the 2011 tsunami, which was higher than $15 \mathrm{~m}$ (Fig. 11, left). As a result, $95 \%$ of the town, including the disaster prevention building, was destroyed (Fig. 11, right), and approximately half of the population was missing immediately after the tsunami. Approximately 1,000 people died or are missing as a result of the tsunami.

Another important issue raised by the 2011 tsunami is that many firemen were lost in the call of duty as they closed many tsunami gates and the gates of seawalls. Two-hundred and fifty-four casualties were reported in Iwate, Miyagi, and Fukushima prefectures, and more than 70 of these were while closing these gates (Yomiuri NEWSPAPER, 2011a). 

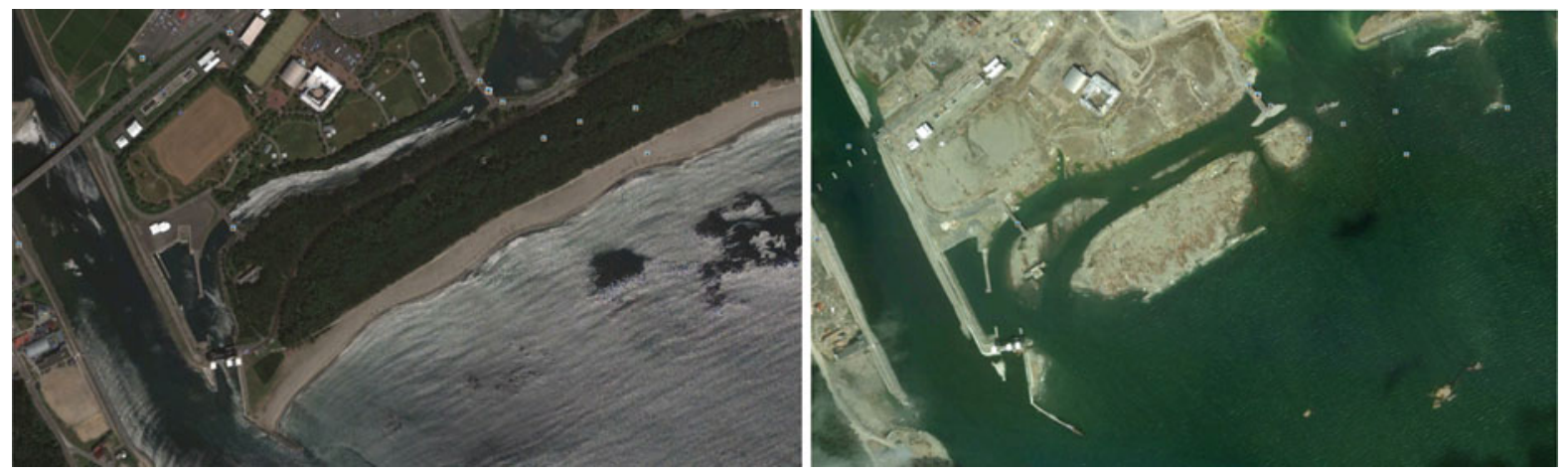

Figure 12

Control forest in Rikuzen-Takata city. Approximately 70,000 pine trees were completely swept away
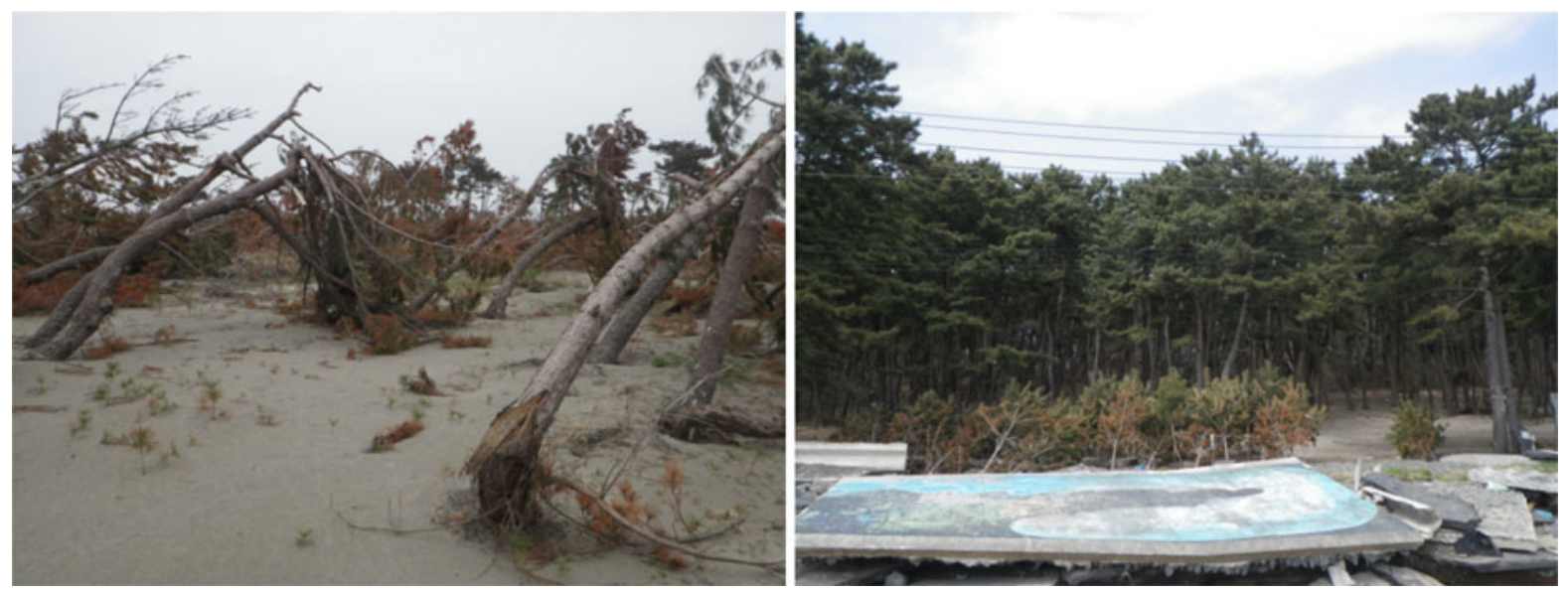

Figure 13

Damage to a control forest in Natori city (11/5/2011), and a control forest that survived in Ishinomaki city (26/4/2011)

According to a questionnaire given to 471 firemen in 5 cities (Miyako, Kamaishi, Kesennuma, Ishinomaki, and Iwaki) (KAHOKU NEWSPAPER, 2011), $61 \%$ of firemen met at their office and went out for duty. Among them, $23 \%$ went to the coast to close the gates, and $47 \%$ went to help the evacuation. The percentages of fireman killed by the tsunami were $22 \%$ during gate-closing work and $31 \%$ during evacuation work. Thus, the Japanese government has a plan to install a new system to control these gates remotely.

\subsection{Control Forests}

An example of a great loss of control forests is in Rikuzentakata city. The city is known for having a $2 \mathrm{~km}$ stretch of shoreline lined with $\sim 70,000$ pine trees (Fig. 12, left). The 2011 tsunami, which was nearly $20 \mathrm{~m}$ high, swept away the entire forest; only one $10 \mathrm{~m}$ high, 200-year-old tree remains (Fig. 12, right). This surviving tree became a very important symbol of the reconstruction for people in the city. The forest not only could not protect the town but also increased the impact of the tsunami because of floating debris.

In Natori, where Sendai airport is located, a tsunami with a height of 10-12 m, as measured from garbage remaining on trees (SUPPASRI et al., 2012b), overturned most of the trees (Fig. 13, left); however, the control forest helped to protect the airport, because the tsunami inundation depth was only $4 \mathrm{~m}$.

Unlike the first two examples, almost all of the pine trees in the control forest in Ishinomaki survived (Fig. 13, right). The forest reduced the destructive 

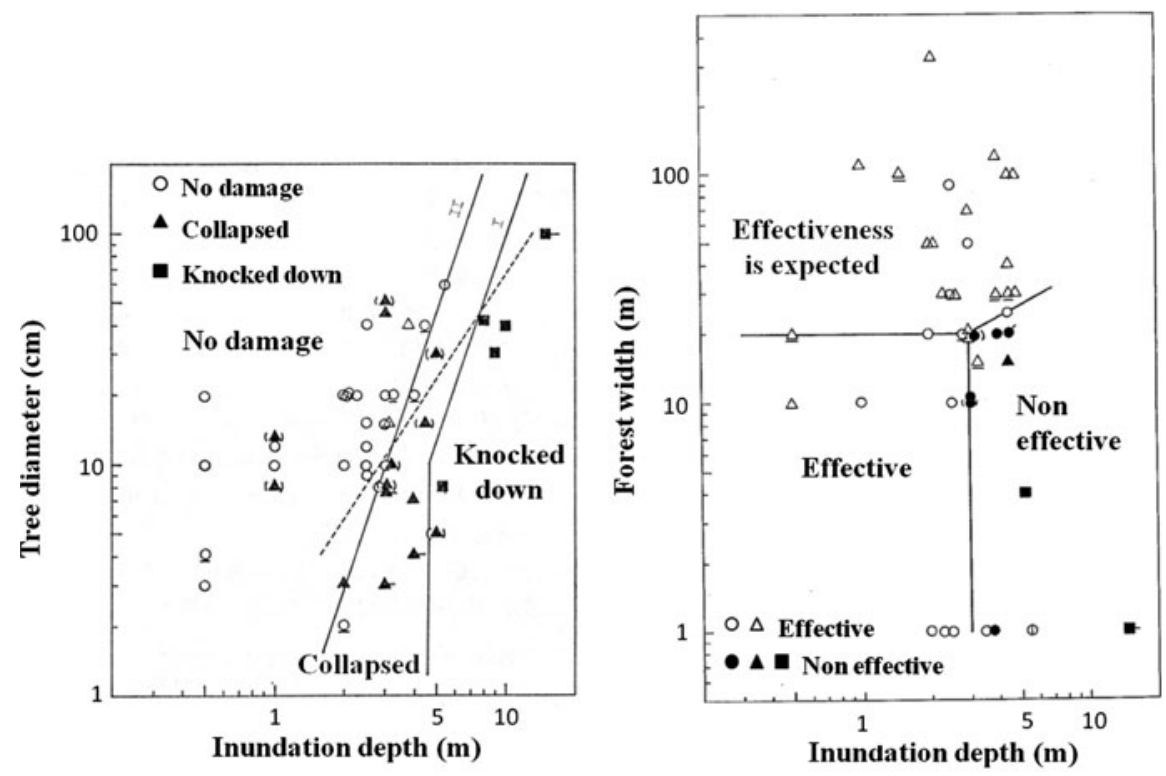

Figure 14

Tree damage as a function of inundation depth and tree diameter, and the effectiveness of control forests as a function of inundation depth and forest width (SHuto, 1985)

power of the tsunami and trapped debris, for example cars, from the water before it entered the city. The trees may have been saved because the height of the tsunami at Ishinomaki was lower $(\sim 6 \mathrm{~m})$. The seawall (which was later destroyed) may also have helped protect the trees. YomiURI NEWSPAPER (2011b) reported results based on the estimates from a field survey of tsunami-affected areas conducted by the Forestry and Forest Products Research Institute. Without control forests, it is predicted that a $16 \mathrm{~m}$ high tsunami would have inundated $600 \mathrm{~m}$ in $18 \mathrm{~min}$ with an average velocity of $10 \mathrm{~m} / \mathrm{s}$. However, with the control forest, the tsunami arrival time was delayed by $6 \mathrm{~min}$, and its velocity was reduced to $2 \mathrm{~m} / \mathrm{s}$.

In general, control forests can withstand tsunamis up to 3-5 $\mathrm{m}$ high, on the basis of historical Japanese tsunami data in 43 locations, namely, 1896 MeijiSanriku, 1933 Showa-Sanriku, 1946 Nankai, 1960 Chile, and 1983 Japan Sea, as shown in Fig. 14, left and right (Shuto, 1985). The circles indicate trees that have survived whereas triangles and the rectangles indicate trees that collapsed or were cut down, respectively. For example, a tree with a diameter of $10 \mathrm{~cm}$ can withstand a tsunami inundation depth up to $3 \mathrm{~m}$ but will collapse or be cut down if the inundation depth is greater than 4 and $5 \mathrm{~m}$, respectively. Figure 14, right, shows the effectiveness of the control forest in trapping debris and reducing the wave current. The effectiveness of the control forest was limited at an inundation depth of $3 \mathrm{~m}$ for a forest width of $<20 \mathrm{~m}$. Historical data show that a forest width $>100 \mathrm{~m}$ is expected to be effective up to an inundation depth of $5 \mathrm{~m}$. The maximum 2011 tsunami heights in both Rikuzen-Takata (150 m forest width) and Natori (500 $\mathrm{m}$ forest width) were $>10 \mathrm{~m}$ (out of the data range), and caused devastating damage. On the other hand, a $6 \mathrm{~m}$ tsunami attacked the control forest in Ishinomaki (150 m forest width); the damage that was caused is shown in Fig. 14, left.

Figure 15 shows a good example of how control forests and breakwaters could have helped to reduce the damage to areas behind them in Ishinomaki city. This figure was created by visual inspection of satellite images, with gray indicating the area of tsunami inundation by the 2011 tsunami, red indicating the areas where houses were washed away, and blue indicating the areas with surviving houses (TEL, 2011). It is very clear that the number of houses washed away in zone B (behind the control forest) is much smaller than that in zone A (without a control 


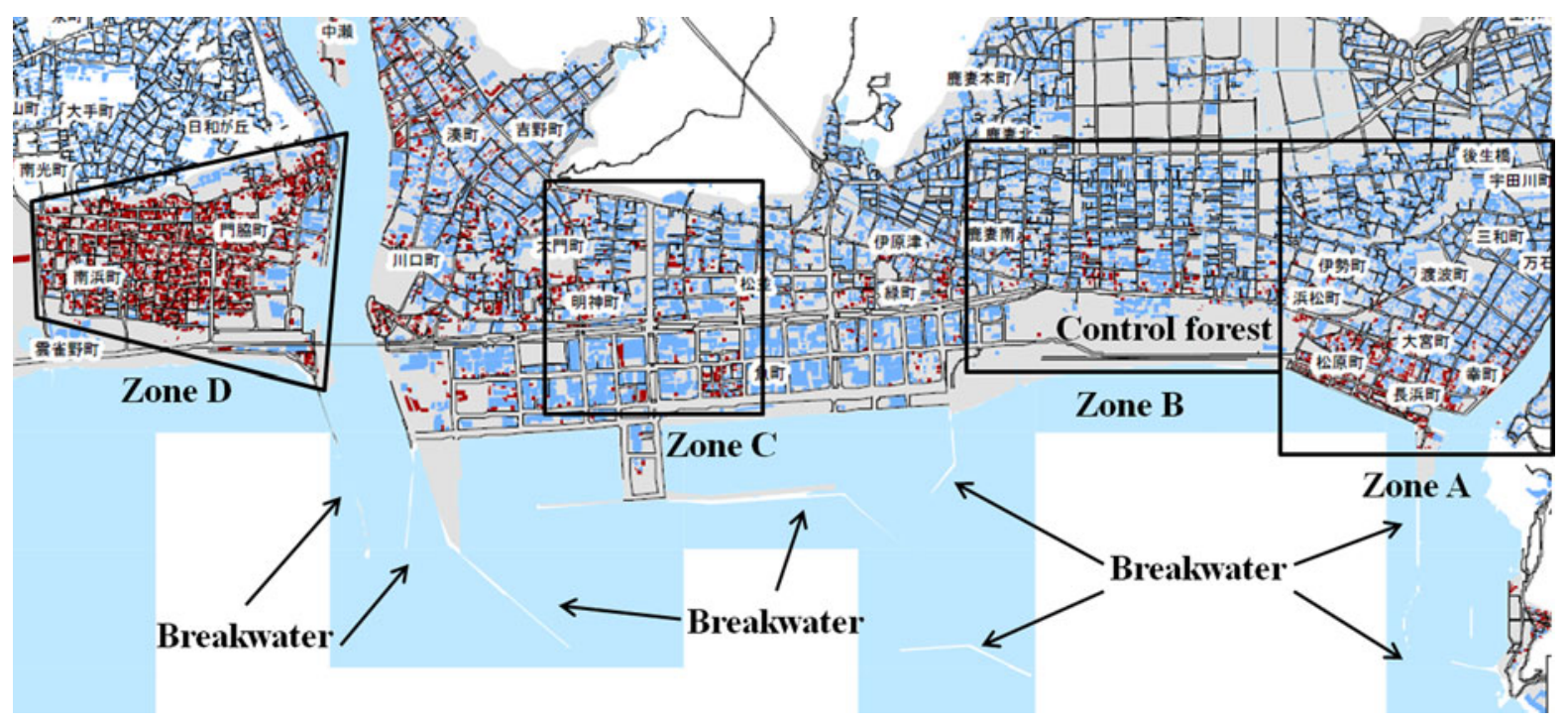

Figure 15

Tsunami damage reduction effect because of the control forest and breakwaters in Ishinomaki city

forest). GoKon and Koshimura (2012) showed that the probability of a building being washed away in zone C (inside the breakwaters) was $\sim 40 \%$, whereas in zone D (outside the breakwaters), it was almost as high as $90 \%$, confirming the $50 \%$ reduction effect, although both areas experienced a maximum tsunami height lower than $7 \mathrm{~m}$.

\section{Residential Structures}

\subsection{Residential Houses}

The tsunami left 115,163 houses heavily damaged, 162,015 houses moderately damaged and 559,321 houses partially damaged (NATional Police AgEnCy, 2011). Most houses in residential areas are constructed from wood. The relationship between the tsunami hazard level and the structural damage is described by tsunami fragility curves. Figure 16, left shows the tsunami fragility curves that were developed, using data from the 1993 Okushiri tsunami (most of the houses were constructed out of wood) (Koshimura et al., 2009). These curves indicate that the probability of damage (destroyed or washed away) is very high when the tsunami inundation depth exceeds $2 \mathrm{~m}$. The structural materials and the number of stories are directly related to the probability of damage. For example, the probability of damage (destroyed or washed away) from a tsunami with an inundation depth of $4 \mathrm{~m}$ is $0.3,0.7$, and 0.9 for a reinforced concrete (RC) house, a mixed-type house in Thailand (SUPPASRI et al., 2011), and a wooden house, respectively (Fig. 16, left). For the same tsunami, the probability of damage is 0.9 for a one-story house and 0.5 for a house that has more than one story (Fig. 16, right). Figure 17, top, shows examples of three damaged houses. Although all three houses experienced an inundation depth of $4 \mathrm{~m}$, the level of damage is different, depending on building typology. In Fig. 17, bottom, the first building on the left side (green rectangle) is a twostory $\mathrm{RC}$ office that sustained broken windows but no structural damage. The two-story wooden house in the center (yellow rectangle) sustained damage to some of its walls and columns. The one-story wooden house on the right (red rectangle) completely collapsed. However, the impact from floating debris is complex and difficult to ascertain at this time. In fact, the velocity of the tsunami wave current was also important in the structural destruction, because of the hydrodynamic force. Nevertheless, the current velocity is quite difficult to measure using only tsunami traces found during field surveys, especially along the Sanriku ria coast, where the tsunami wave easily accumulated such hydrostatic and hydrodynamic force that the tsunami height and velocity became 

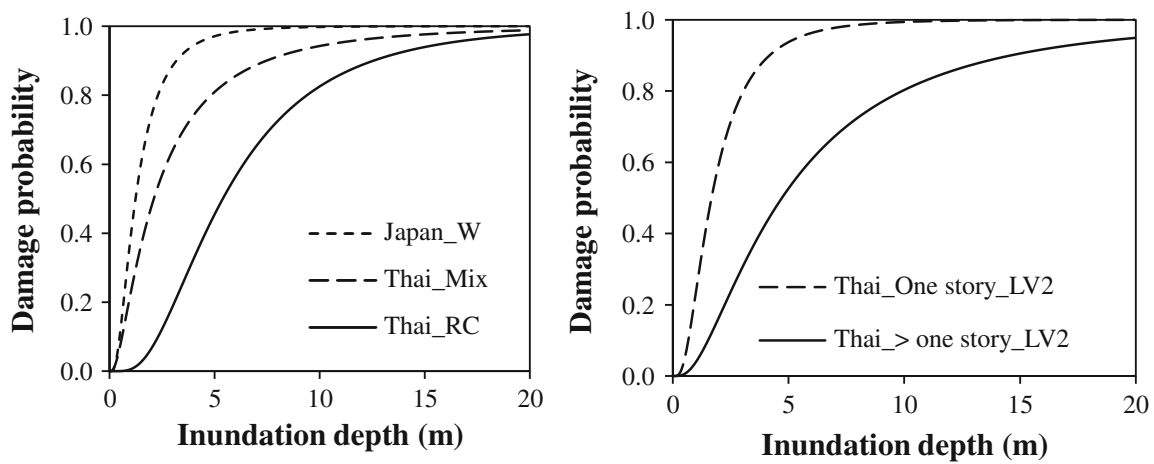

Figure 16

Tsunami fragility curves for different types of structural material and for different numbers of stories (KosHIMURA et al., 2009; SUPPASRI et al., 2011)
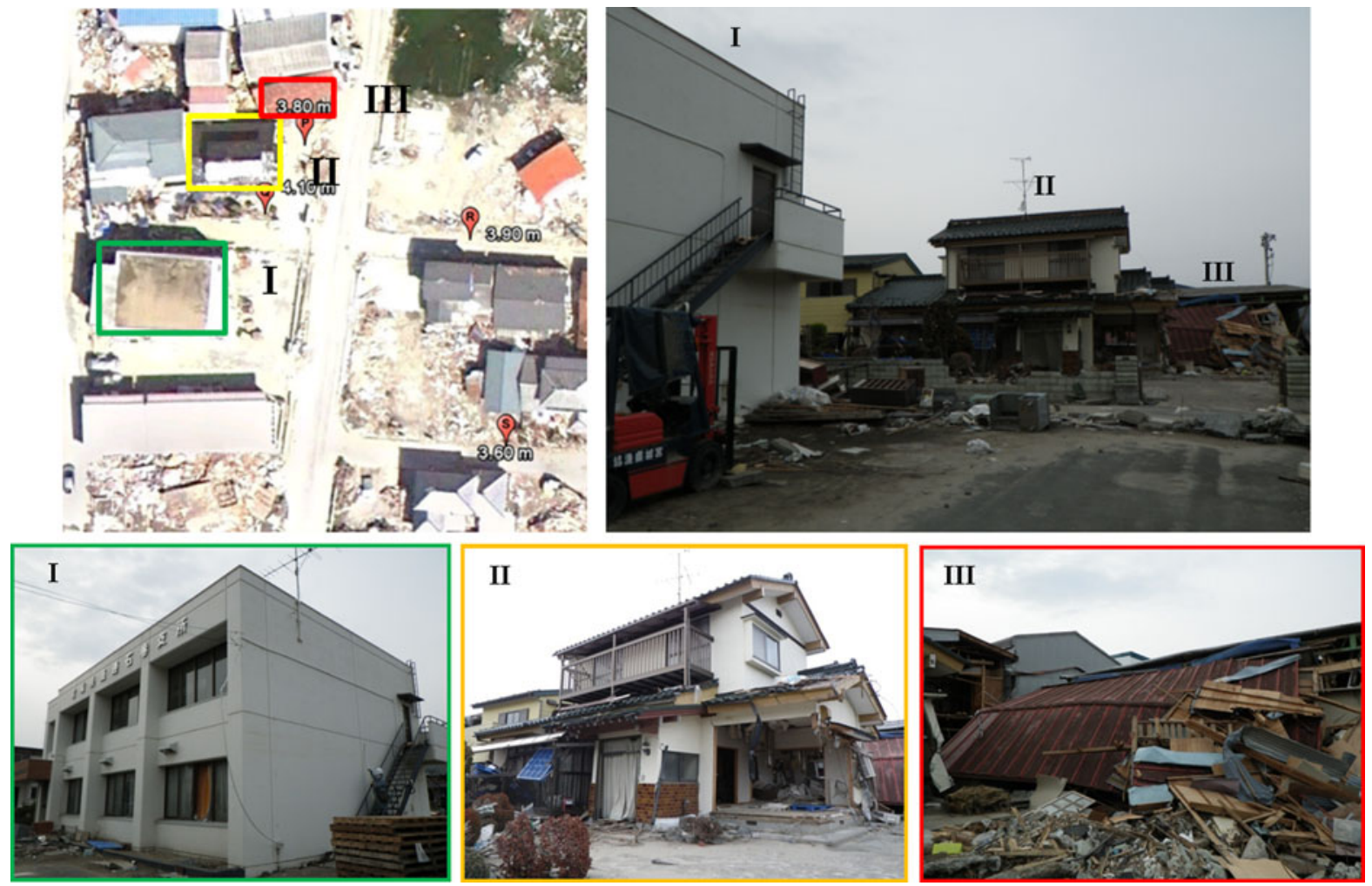

Figure 17

Examples of different damage levels for the same tsunami inundation depth (26/4/2011)

larger than in the Sendai coastal plain. Comparison of the housing damage ratio between the plain and ria coast of Ishinomaki city shows that the damage ratio for houses washed away at $3 \mathrm{~m}$ of inundation depth was 0.1 along the plain coast but as high as 0.6 along the ria coast (SuPPASR et al., 2012b). This result confirms the effect of current velocity on different damage levels at the same inundation depth. 

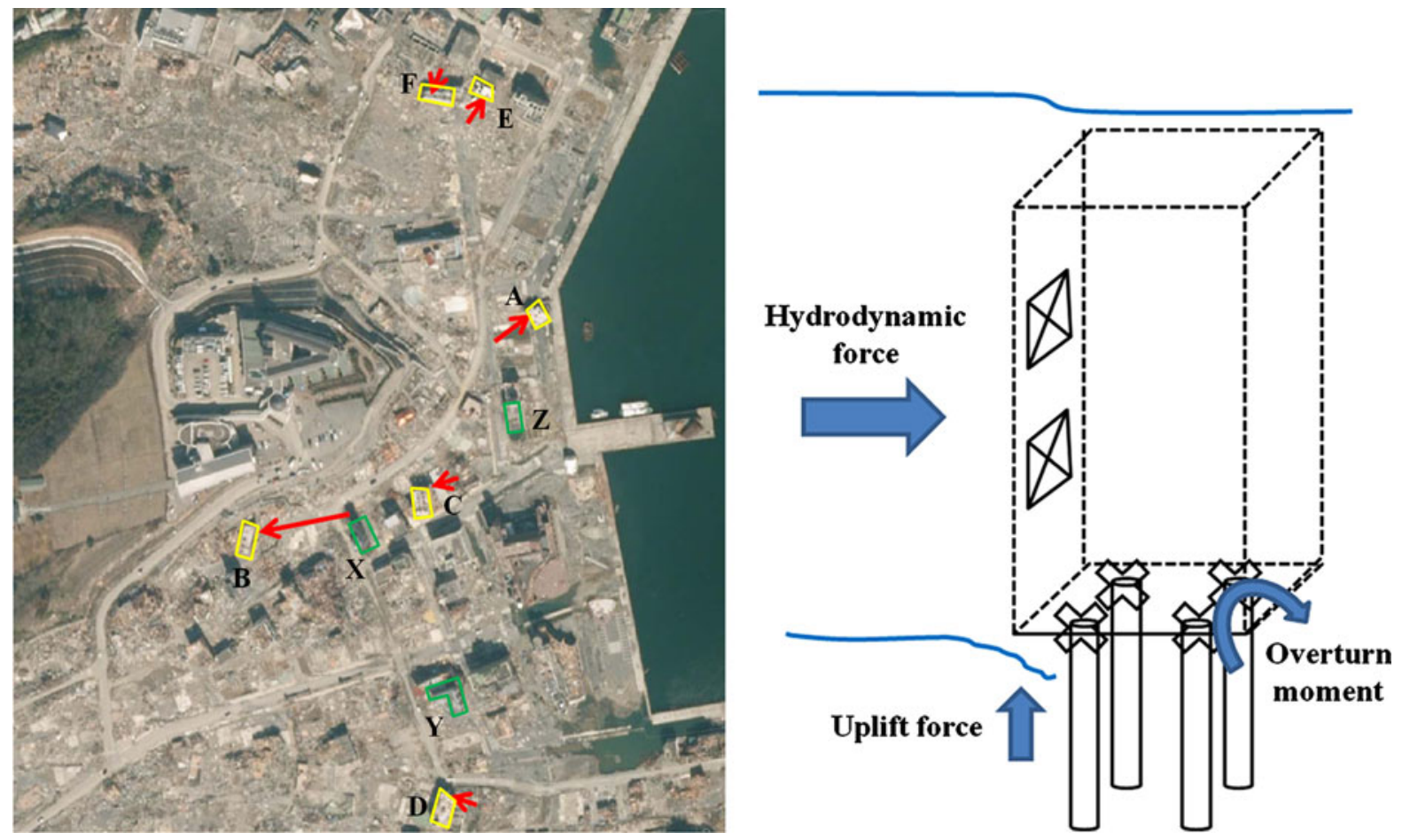

Figure 18

Six buildings that were overturned $(A-F)$ in Onagawa town and the mechanisms that mediated overturning

\subsection{Commercial and Public Buildings}

In tsunamis it is usually recommended that people evacuate to high-rise RC buildings or steel-reinforced concrete (SRC) buildings if there are no mountains nearby. The building code for earthquake-resistant buildings was revised in 1981 and 2000 but did not take into account tsunami load. The guideline for tsunami evacuation buildings was established in 2005 (CABINET OfFice, 2005). The practical instruction for evacuation of buildings stated in the guideline is to evacuate to higher than the third or fourth floor if the expected tsunami inundation depth is 2 or $3 \mathrm{~m}$, respectively. However, the 2011 tsunami shows that this guideline may not always be correct. There are six overturned buildings in Onagawa town (Fig. 18, left), and two each in Akamae village, Miyako city, Otsuchi town, and Rikuzen-Takata city. None of these were tsunami evacuation buildings, and they were not designed to resist tsunami loads. The fourstory RC building (building B) pictured in Fig. 19, right, was moved $70 \mathrm{~m}$ from its original location before stopping at a hill (Fig. 20, left). However, a five-story RC building (building X) survived and did not overturn (Fig. 19, left), even though it was in the same place.

The reasons these buildings may have overturned are as follows (Fig. 18, right):

- First, many pile foundations were damaged by the strong shaking and soil liquefaction that preceded the tsunami which reduced the frictional resistance of the pile foundations. A large lateral load occurred during the earthquake, and liquefaction might have caused cap failure. In other words, pile connections failed, and the cap could not resist overturning moments from the vertical load of the building and lateral hydrodynamic load of the tsunami. The building that is pictured in Fig. 20, right had only one pile remaining.

- Second, because of the ria coast, the tsunami was amplified by a narrow bathymetry and resulted in runup heights of $15-20 \mathrm{~m}$, as measured near the locations of the overturned buildings. The tsunami, which was generated by a large earthquake (large fault width), had a long wave period, which led to a 

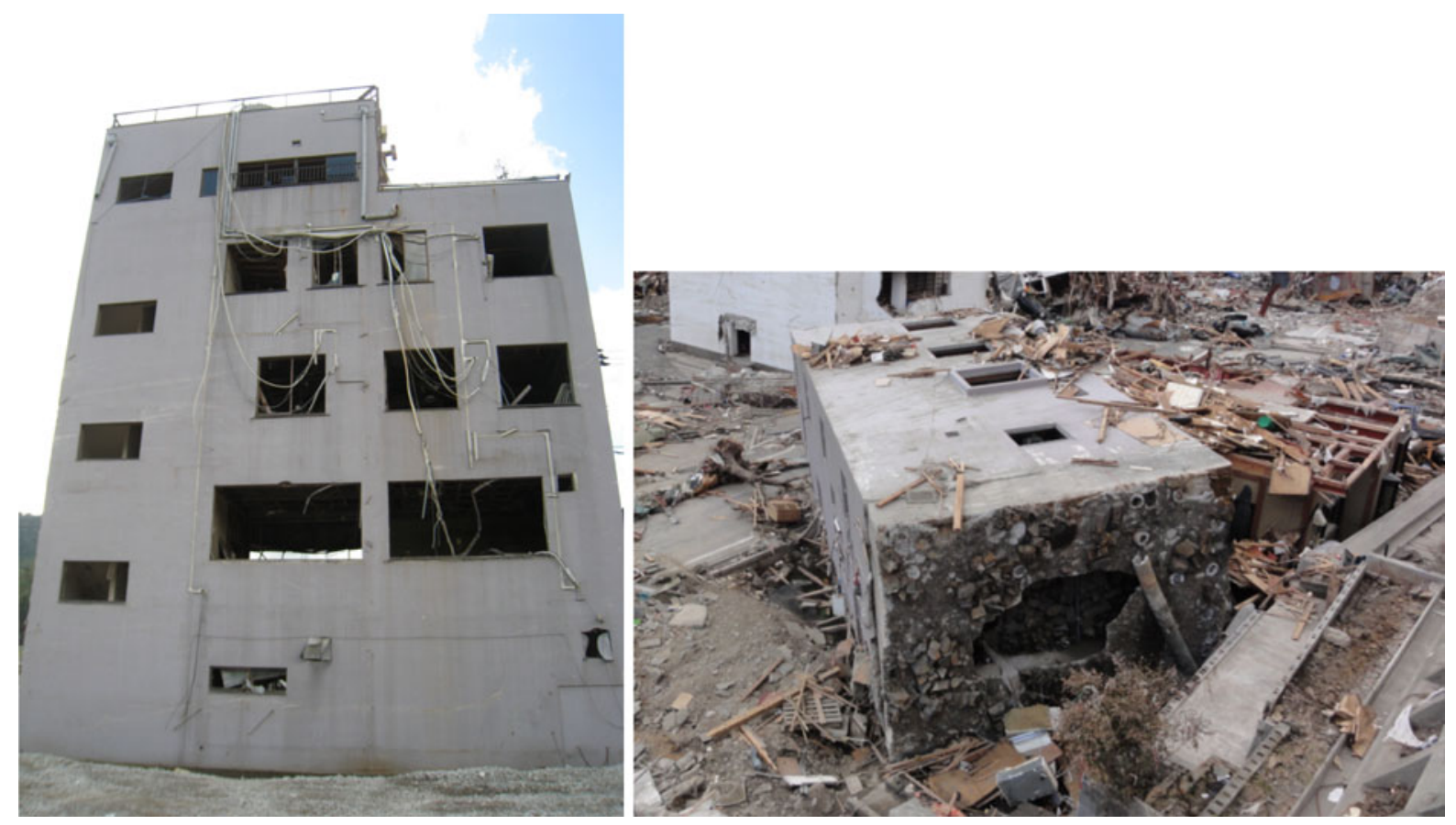

Figure 19

Building X (sea front), which survived (29/9/2011), and building B, which was overturned (29/3/2011)
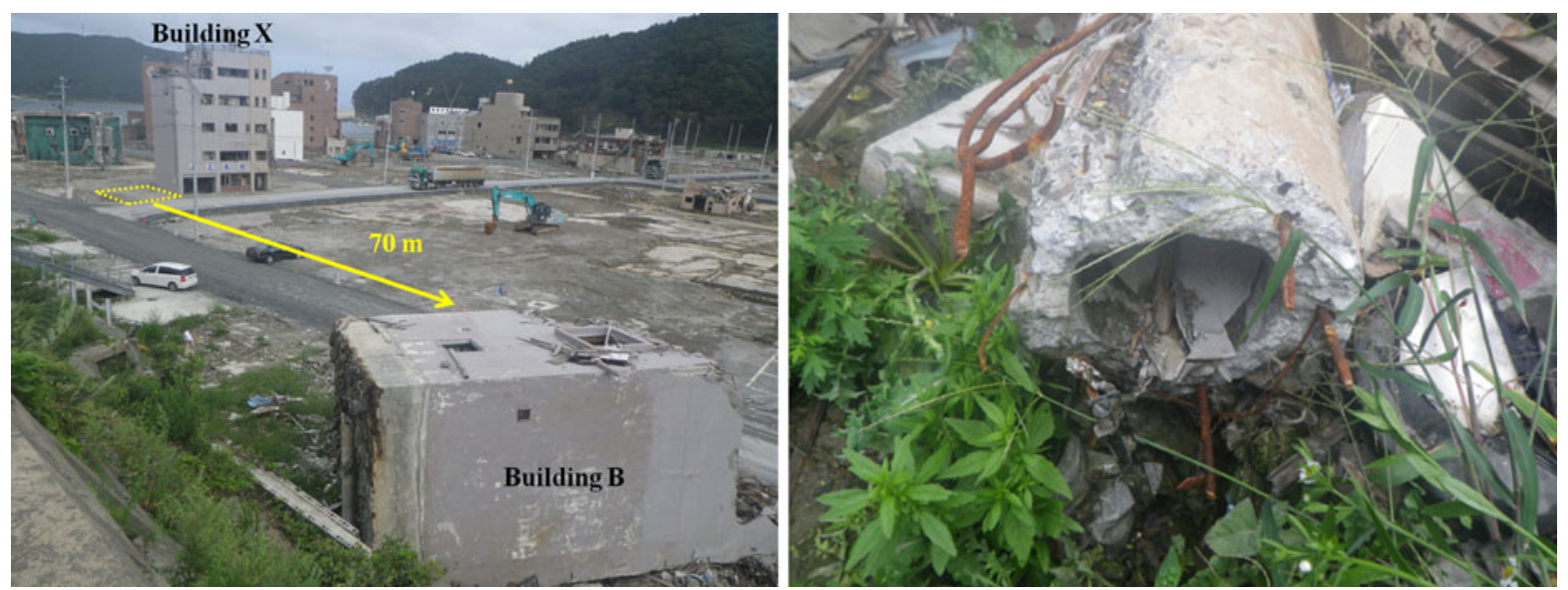

Figure 20

Building B, which was moved $70 \mathrm{~m}$ from its original location (upper-left corner), and a detailed picture of a pile foundation from building B $(3 / 9 / 2011)$

long time of interaction of the tsunami force acting on the buildings.

- Third, the ratios of openings (windows and doors) to walls in the overturned buildings were small. Therefore, pressure suddenly accumulated at the tsunami-facing wall, which caused local scouring at the foundations. Table 3 summarizes detailed information on the overturned and non-overturned RC buildings in Onagawa town, as measured during field surveys. Most of the buildings in Onagawa town (including buildings $\mathrm{C}$ and $\mathrm{E}$ ) were overwhelmed by the tsunami, except building $\mathrm{X}$. 
Table 3

Information about overturned and non-overturned RC buildings in Onagawa town

\begin{tabular}{llccccccc}
\hline ID & Story & $\begin{array}{l}\text { Building } \\
\text { height }(\mathrm{m})\end{array}$ & $\begin{array}{l}\text { Opening } \\
\text { area }\left(\mathrm{m}^{2}\right)\end{array}$ & $\begin{array}{l}\text { Opening } \\
\text { ratio }(1)\end{array}$ & $\begin{array}{l}\text { Footing } \\
\text { area }\left(\mathrm{m}^{2}\right)\end{array}$ & $\begin{array}{l}\text { Length/ } \\
\text { width }(2)\end{array}$ & $\begin{array}{l}\text { (1)/(2) } \\
\text { of overturn }\end{array}$ \\
\hline $\mathrm{A}$ & 2 & 10.5 & 6.6 & 0.0524 & 68.4 & 2.11 & 0.024 & Sea \\
$\mathrm{B}$ & 4 & 14.0 & 4.3 & 0.0427 & 26.6 & 1.95 & 0.022 & Land \\
$\mathrm{D}$ & 2 & 10.5 & 19.72 & 0.0806 & 172.4 & 3.15 & 0.026 & Land \\
$\mathrm{E}$ & 2 & 7.0 & 7.71 & 0.1039 & 42.4 & 2.65 & 0.039 & Land \\
$\mathrm{X}$ & 5 & 17.3 & 38.64 & 0.1679 & 90.4 & 1.95 & 0.086 & - \\
$\mathrm{Y}$ & 4 & 13 & 121.5 & 0.5841 & 208.0 & 1.23 & 0.475 & - \\
$\mathrm{Z}$ & 2 & 8.5 & 19.25 & 0.1258 & 153.0 & 2.12 & 0.059 & - \\
\hline
\end{tabular}

Most of buildings are pile foundation except for building A, which is shallow foundation. Building C is steel frame with ALC wall building and building $\mathrm{F}$ is an RC building but the town removed the building before the measurements were performed. At present, only three buildings (A, C, and E) will remain as memorial parks

The overturned buildings were directed toward land, meaning that they were overturned by the striking wave and not the receding wave. It is very clear that all of the overturned buildings had an opening area equal to or less than $10 \%$.

- Fourth, buoyancy created an uplifting force that raised the buildings. All of the overturned buildings were overwhelmed by the tsunami, resulting in a large uplift force because of buoyancy. In some cases, buried structures can literally be floated out of the ground because of the increased pore water pressures. In addition, there was sufficient time for water to flow inside the buildings, because of the long period of the wave, which increased the vertical load of the building. Accumulated air between the top level of the windows and the ceiling also generated buoyancy.

- Fifth, because of outdated structural design codes, the buildings had poor reinforcement against longitudinal and lateral pressure (Fig. 20, right). Most were probably constructed during 1970-1980, before the new building design code for earthquakeresistant buildings in 1981.

All of these phenomena and forces generated an overturning moment on the buildings.

\subsection{Evacuation Buildings and Shelters}

There were many designated evacuation buildings and shelters that failed to protect lives because of the unexpected tsunami height and runup. For instance, a community gym was designated as an evacuation shelter in the flat region of Rikuzen-Takata city.
The tsunami overwhelmed the gym, and only three people survived out of more than 80 evacuees. Another example in Rikuzen-Takata is a five-story residential building (Fig. 21, left). The tsunami reached only the fourth floor; however, the building had no stairway that would enable people to evacuate to the roof in the case of a larger tsunami. Another example of an unfortunate result of the unexpected tsunami was at Okawa primary school (Fig. 21, right), located near the mouth of a river. The tsunami claimed 74 out of a total of 108 children and 10 staff. Most of the children that survived climbed the mountain behind the school; the others went to the bridge where they were struck by the tsunami. The school had not conducted evacuation drills and had no tsunami plans before the 2011 event.

Officers and staff members that were stationed at the Otsuchi town office (Fig. 22, left) and the disaster prevention building (Fig. 22, right) in MinamiSanriku also lost their lives. In Otsuchi town, the town leader and his staff lost their lives; this loss has caused the reconstruction process in Otsuchi town to be slower than at other locations. A staff member in Minami-Sanriku town lost her life while announcing the evacuation; other staff members inside the building also lost their lives.

In the Unosumai area of Kamaishi city there is a famous story called "Miracles of Kamaishi" because all 580 students and teachers from two schools survived the tsunami even though their schools were destroyed by the tsunami. Although their schools were located outside the expected tsunami inundation area, on the basis of historical records, the students 

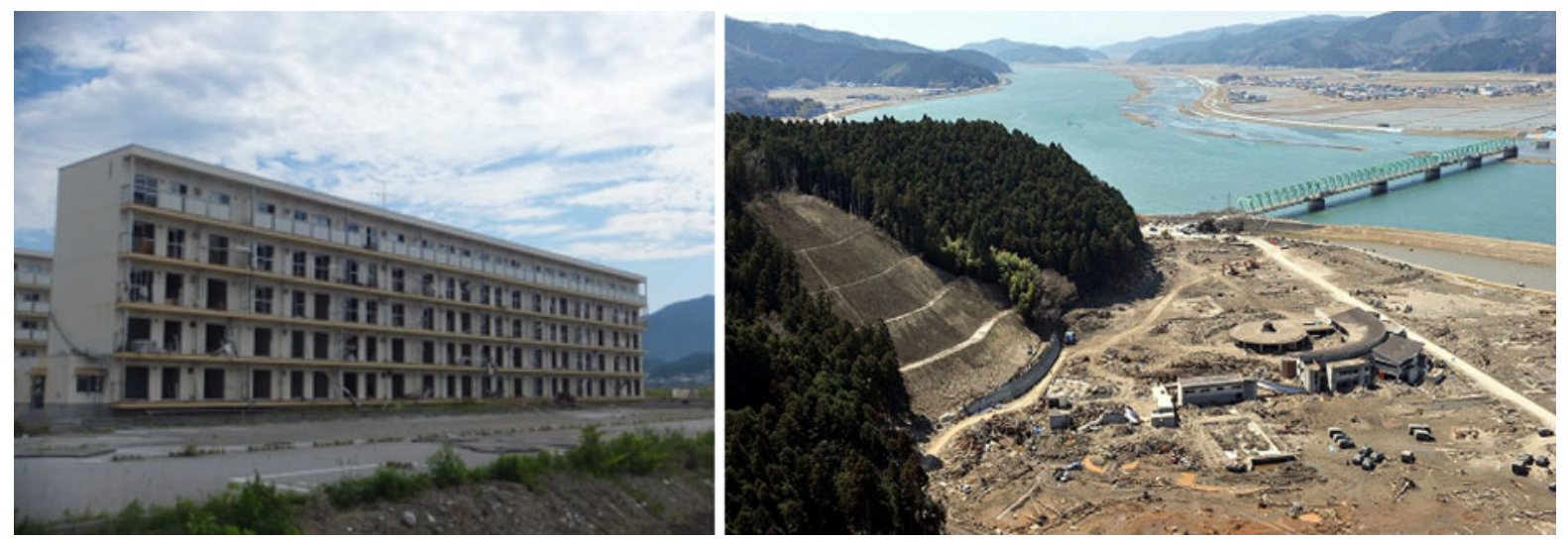

Figure 21

A five-story apartment building in Rikuzen-Takata city, and Okawa primary school
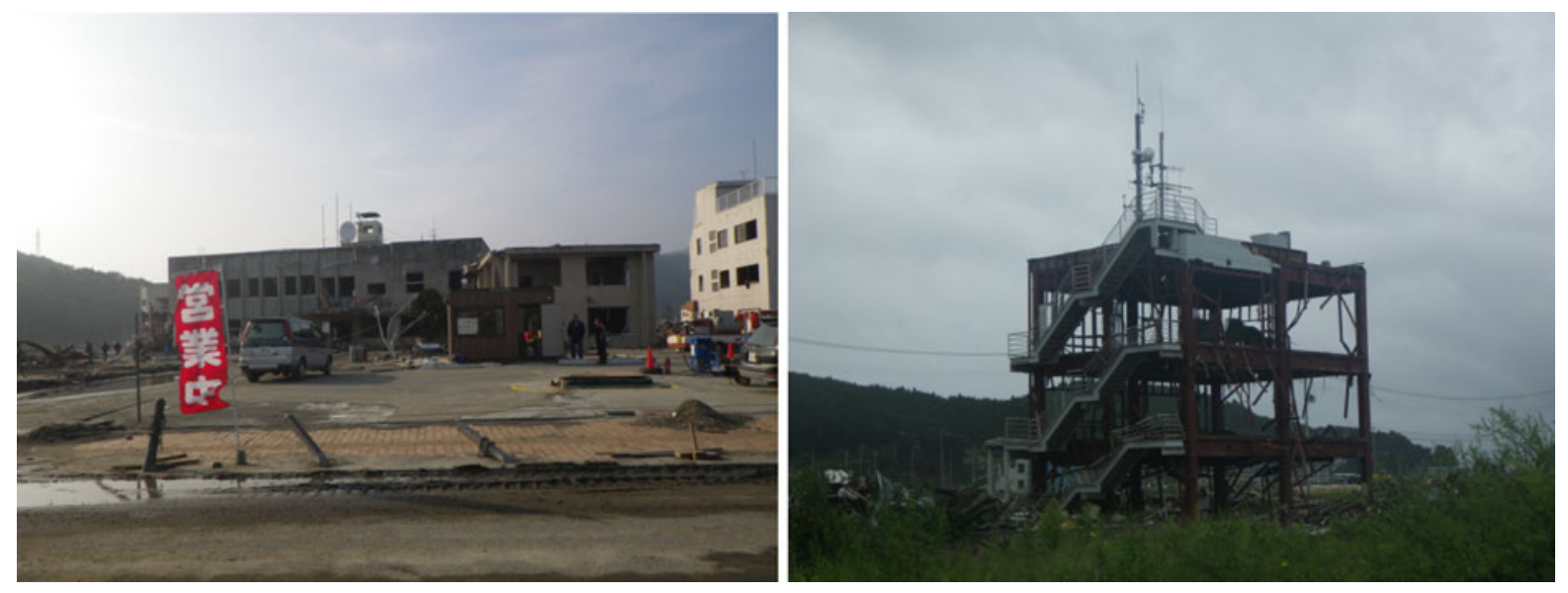

Figure 22

The Otsuchi town office (31/5/2011) and the disaster prevention building in Minami-Sanriku town (3/9/2011)

decided to leave their schools and evacuate to higher ground, and all of them survived. However, there was also great loss in this area because of an incomplete evacuation drill. The evacuation drill was performed on 3rd March (the memorial day of the ShowaSanriku tsunami), $\sim 1$ week before the tsunami. The town selected the two-story RC building as the disaster prevention center (a group evacuation shelter located outside the expected inundation area) rather than other evacuation areas on high ground, because the center is easily accessible by the elderly. A fatal tragedy occurred when most of the evacuation drill participants evacuated to the center rather than to high ground. As a result, there were only 25 confirmed survivors from the total 200 evacuees, with 54 found dead inside the center and the number of estimated dead and missing $>100$.

Some other successful cases are reported here. Onagawa town hospital is located $\sim 15 \mathrm{~m}$ above the sea level, and the tsunami reached the first floor (Fig. 23, left). A school in Ishinomaki city that was located behind the control forest was inundated to the second floor (Fig. 23, right). The tsunami reached the first floor at the sightseeing ferry terminal in Shiogama city; the evacuation sign suggests evacuating to the second or third floor (Fig. 24, left). Last, a school in Arahama town was the only building in the area that was located on high ground; it survived because the tsunami reached the second floor only (Fig. 24, right). 

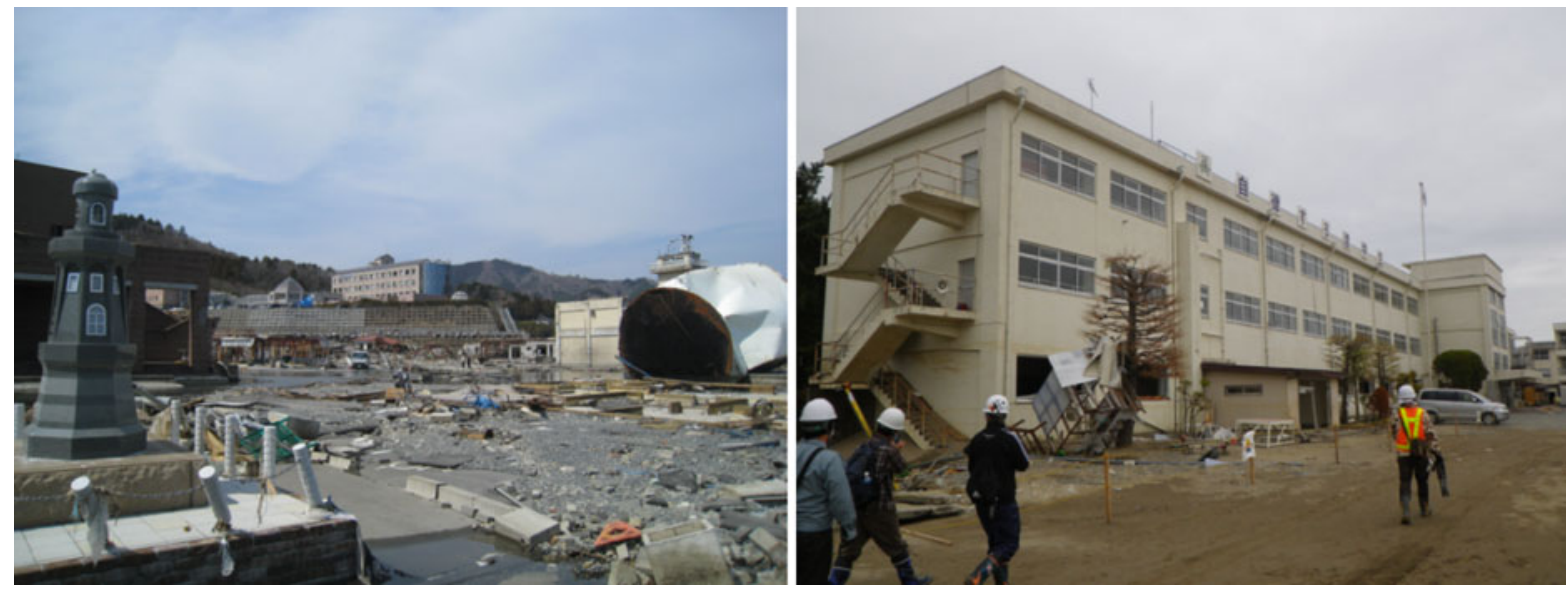

Figure 23

Evacuation buildings in Onagawa town (29/3/2011) and Ishinomaki city (12/5/2011)
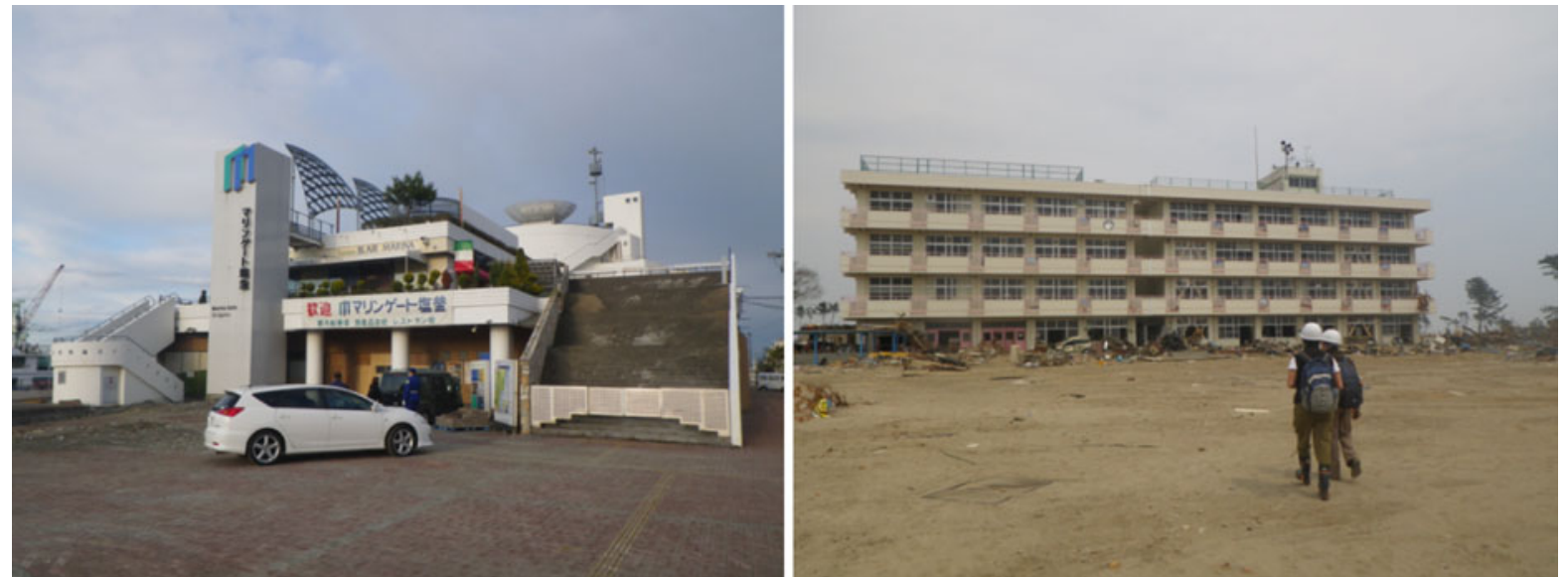

Figure 24

Evacuation buildings in Shiogama city (29/4/2011) and Arahama town (16/4/2011)

To summarize, in the entire Tohoku region the three worst designated evacuation shelter locations inundated by the tsunami (MuRAI, 2011) were those for RikuzenTakata: Iwate prefecture (35 out of 68 places, $51.5 \%$ ), Onagawa (12 out of 25 places, $48 \%$ ), and MinamiSanriku (31 out of 78 places, $39.7 \%$ ), leading to fatalities at the three locations as high as 11.7, 11.2, and $6.3 \%$, respectively (SUPPASRI et al., 2012a).

\section{Tsunami Awareness and Disaster Mitigation}

\subsection{Tsunami Experience and Awareness}

People who live along the Sanriku coast have more experience of tsunamis than those who live on the Sendai plain. The occurrence of two huge tsunamis in 37 years (the 1896 Meiji tsunami and the 1933 tsunami) taught the residents of the Sanriku coast about the dangers of tsunamis. From the questionnaire results (CeMI, 2011), $90 \%$ of the people in Kamaishi city evacuated quickly, with $60 \%$ of them starting their evacuation $<10 \mathrm{~min}$ after the earthquake, whereas only $60 \%$ of the people in Natori city evacuated quickly, and $30 \%$ of them started their evacuation within $30 \mathrm{~min}$ of the earthquake. However, there were many cases documented in the media of people who quickly evacuated to a safe place but then went back to their houses for many reasons and ultimately became casualties. 


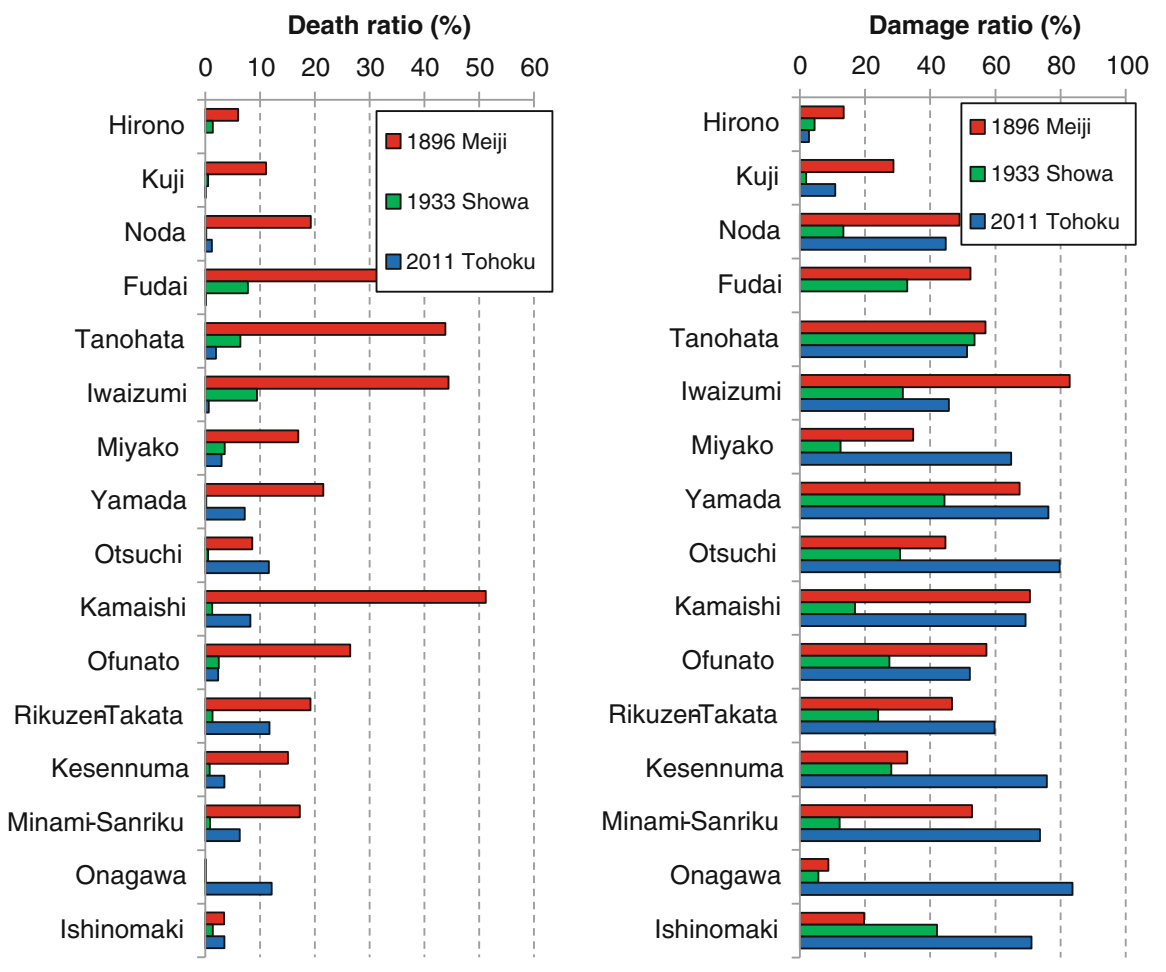

Figure 25

Tsunami deaths and house damage for the Sanriku coastal communities

Historical records from the Sanriku area were used to compare the number of deaths caused and the number of houses damaged (houses that were washed away or sustained major or moderate damage) by the 1896, 1933 (YAMASHITA 2008a, b), and 2011 tsunamis (Iwate PRefecture, 2011; Miyagi Prefecture, 2011). Fatalities as a result of the 1896 tsunami were very high, and not comparable with those of the 1933 and 2011 tsunamis (Fig. 25, left). House damage as a result of the 1896 and 2011 tsunamis are not very different in the Iwate province; however, they are very high for the 2011 tsunami in the Miyagi prefecture because of land development in this area (Fig. 25, right).

Despite high house damage and the largest runup height (Fig. 26, right), fatalities as a result of the 2011 tsunami were much smaller because tsunami experience resulted in the people recognizing the need to evacuate, and evacuating quickly. The tsunami evacuation effect can also be confirmed by the number of deaths per damaged house, which is shown in Fig. 26, left. For the 1896 tsunami, there were more than 2.0-4.5 deaths per damaged house whereas for the 2011 tsunami there are $<0.5$ deaths per damaged house. One reason why the number of deaths for the 1933 tsunami was still high in some locations can be explained by using Taro town as an example. The 1896 tsunami killed nearly $90 \%$ of the people in Taro town. Therefore, most of the people who were affected by the 1933 tsunami were newcomers who had settled in the area after the 1896 tsunami.

Figure 27 shows the relationship between the fatality-to-damage ratio and the maximum runup height of the three tsunamis that affected the Sanriku area, on the basis of data from Yamashita (2008a, b) for the 1896 and 1933 tsunamis, and data from IwATE PREFECTURE (2011) and Miyagi PREFECTURE (2011) for the 2011 tsunami. The 2011 tsunami (Mori et al., 2012) had runup heights in excess of $20 \mathrm{~m}$ in most areas; fatalities were limited to $\sim 10 \%$ whereas damage was as high as $50-80 \%$. Figure 28 shows the death-to-damage ratios as a function of the maximum runup height for the 2011 Tohoku tsunami for two 


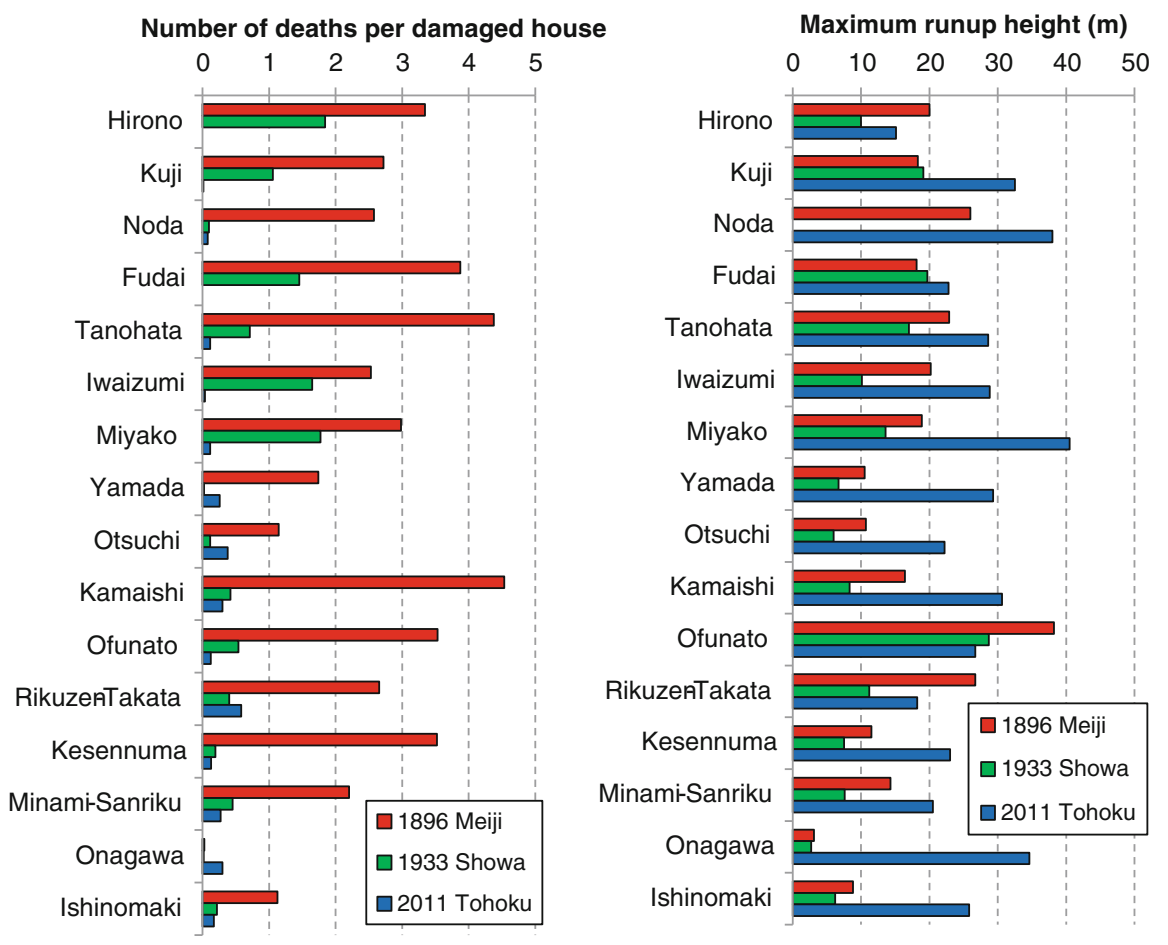

Figure 26

The number of deaths per damaged house and the maximum recorded runup heights for tsunamis that have struck Sanriku coastal communities
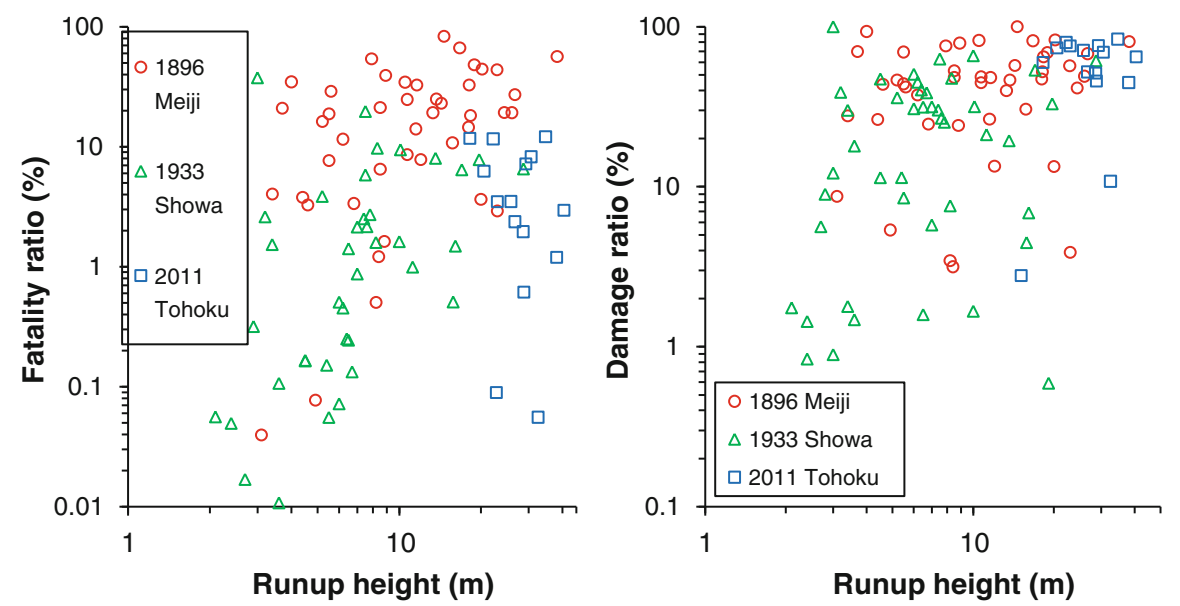

Figure 27

Fatality-to-damage ratio as a function of the maximum runup height for coastal communities along the Sanriku coast and the Sendai plain

different types of coastline: the ria topography along the Sanriku coast and the Sendai plain. The maximum runup height on the Sendai plain was $10 \mathrm{~m}$; however, in some areas, fatalities and house damage were as high as 10 and $75 \%$, respectively. In brief, fatalities and house damage in the Sendai plain were similar to those of the Sanriku ria coast, despite much lower maximum runup heights. 

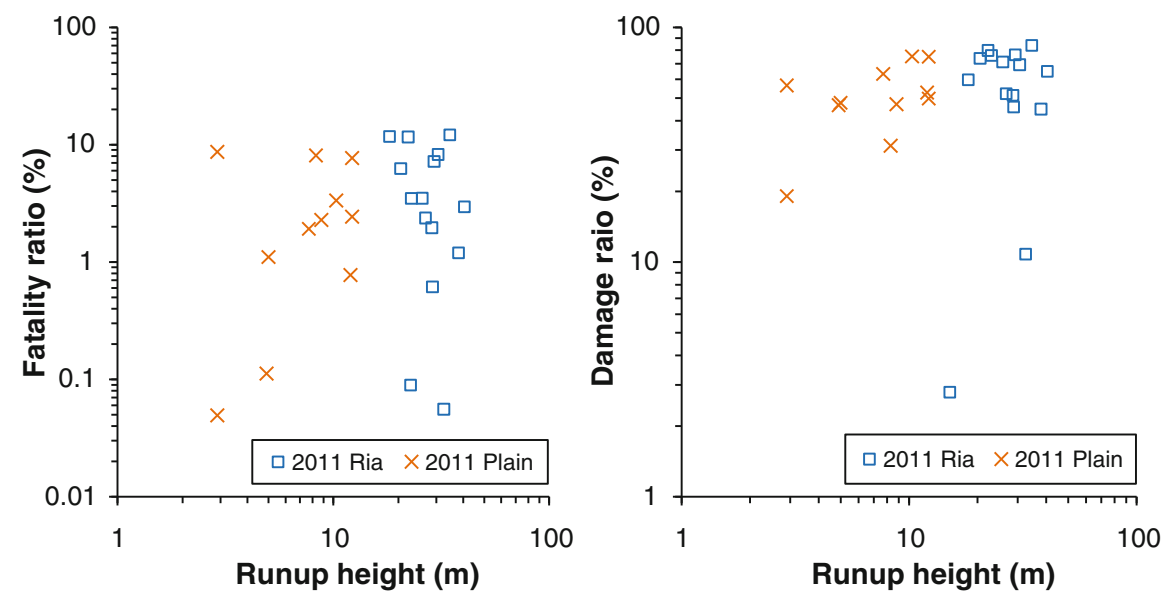

Figure 28

Fatality-to-damage ratios as a function of the maximum runup height of the 2011 Tohoku tsunami for the ria topography along the Sanriku coast and the Sendai plain

\subsection{Self Evacuation}

As mentioned in the section above, experience with tsunamis in the past promoted tsunami awareness in the people of the Sanriku areas. However, there were many cases, including the 2011 event, of people remaining in their house waiting for their family, or taking their belongings after the earthquake, who were ultimately washed away by the tsunami. Self evacuation is very important to prevent this type of tragedy. On the basis of experience from the tsunamis in 1896 and 1933, in which some families lost all of their members because of the tsunami, an idea of self evacuation called "Tsunami tendenko" was proposed (YAmashita, 2008b). "Tsunami tendenko" is a phrase in the dialect of the Sanriku region that is used to encourage people to evacuate from the tsunami alone without taking any belongings or waiting for their family; this phrase can be translated as "you should protect your life by yourself". Therefore, it is acceptable not to blame people who did not help others. The "Miracles of Kamaishi" was a very good example of the practical use of "Tsunami tendenko" because the children started their evacuation by themselves, and all were saved. Examples of similar stories of self evacuation were also reported for the 2004 Indian Ocean tsunami on Surin Islands, Thailand, and Simeulue Island, Indonesia.

\subsection{Residences on High Land}

The Toni-Hongo village was struck by the 1896 tsunami (with a tsunami height of $14.5 \mathrm{~m}$ and 224 houses destroyed) and the 1933 tsunami (with a tsunami height of $9.3 \mathrm{~m}$ and 101 houses destroyed) (Meid University, 2011). After the 1933 tsunami, the village was rebuilt on high land at an elevation of $20 \mathrm{~m}$ (MSL), as shown in Fig. 29, left. The village survived the 1960 Chilean tsunami, which was $\sim 5 \mathrm{~m}$ high. After this event, many houses were built in the lowland areas to accommodate the increasing population, as shown in a picture from 2009 (Fig. 29, center) and a satellite image from 2010 (Fig. 30, left). The 2011 tsunami destroyed the lowland houses but not the highland houses (Figs. 29, right, 30, right).

\subsection{Tsunami Memorials}

Tsunami memorials, for example stone monuments, can be found in many areas along the Sanriku coast. These memorials can be found in MinamiSanriku town, where there are monuments for the 1896 Meiji, 1933 Showa, and 1960 Chile tsunamis. The message on the stone monument for the 1933 Showa tsunami (Fig. 31, left) reads "to be cautious of an abnormal receding wave". However, these monuments, including a $2.6 \mathrm{~m}$ high monument for the 1960 Chile tsunami (Fig. 31, right), were destroyed 

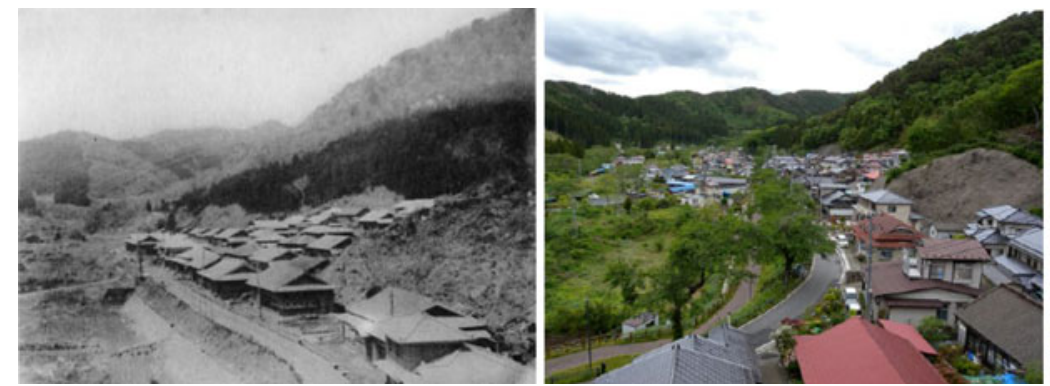

Figure 29

Toni-Hongo village after the 1933 Showa Sanriku tsunami, before the 2011 Tohoku tsunami, and after the 2011 Tohoku tsunami
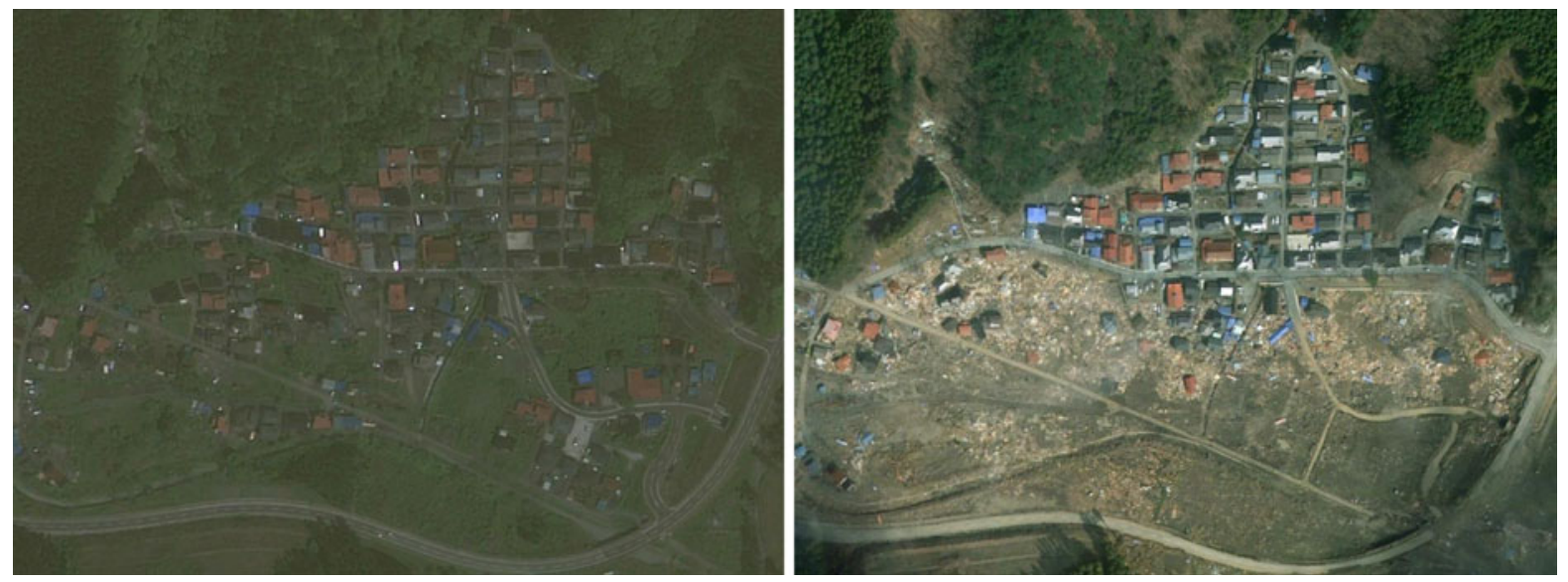

Figure 30

Satellite images of the Toni-Hongo village in May 2010 and in April 2011

by the 2011 Tohoku tsunami. The Namiwake shrine (Fig. 32, left) is a monument in the Sendai area that is located $\sim 5.5 \mathrm{~km}$ from the sea (Fig. 32, right). The shrine is located in a low-lying area in the Wakabayashi ward of Sendai city, and was originally built in 1703. Many flood and tsunami disasters have occurred in this area in the past. In the 1611 Keicho event, the tsunami inundated the shrine's original site, and $\sim 1,700$ people were killed. At one site, the tsunami wave, which approached from the East, was split in the north-south direction; at the time, people believed that the tsunami was created by the god of the sea. In 1835 , the shrine was moved to that site to protect it from the next tsunami; it was given the name "Namiwake" ("Nami" means wave and "Wake" means separate) and is viewed as a symbol of tsunami prevention. In fact, deposits from the 869 Jogan tsunami were found 200-300 m from the front of the shrine. Although the 2011 tsunami was larger than expected, the shrine survived the 2011 Great East Japan earthquake and tsunami (Fig. 32). Additionally, many shrines along the Pacific coast of the Iwate, Miyagi and Fukushima prefectures survived this tsunami. They were built at locations that were regarded as safe on the basis of historical tsunamis, for example the 1611 Keicho tsunami, and left as a warning message to future generations.

\subsection{Tsunami Festivals}

A good example of a tsunami festival in Japan is the festival in the Wakayama prefecture that celebrates a real story titled "Inamura no Hi". The story originated from the Nankai tsunami in 1854. Hamaguchi Goryo (Fig. 33, left), the leader of Hirogawa town in Wakayama province, noticed a tsunami after a strong shake (WAKAYAMA BROADCAST, 2009). He knew that it would be difficult to convince people to 

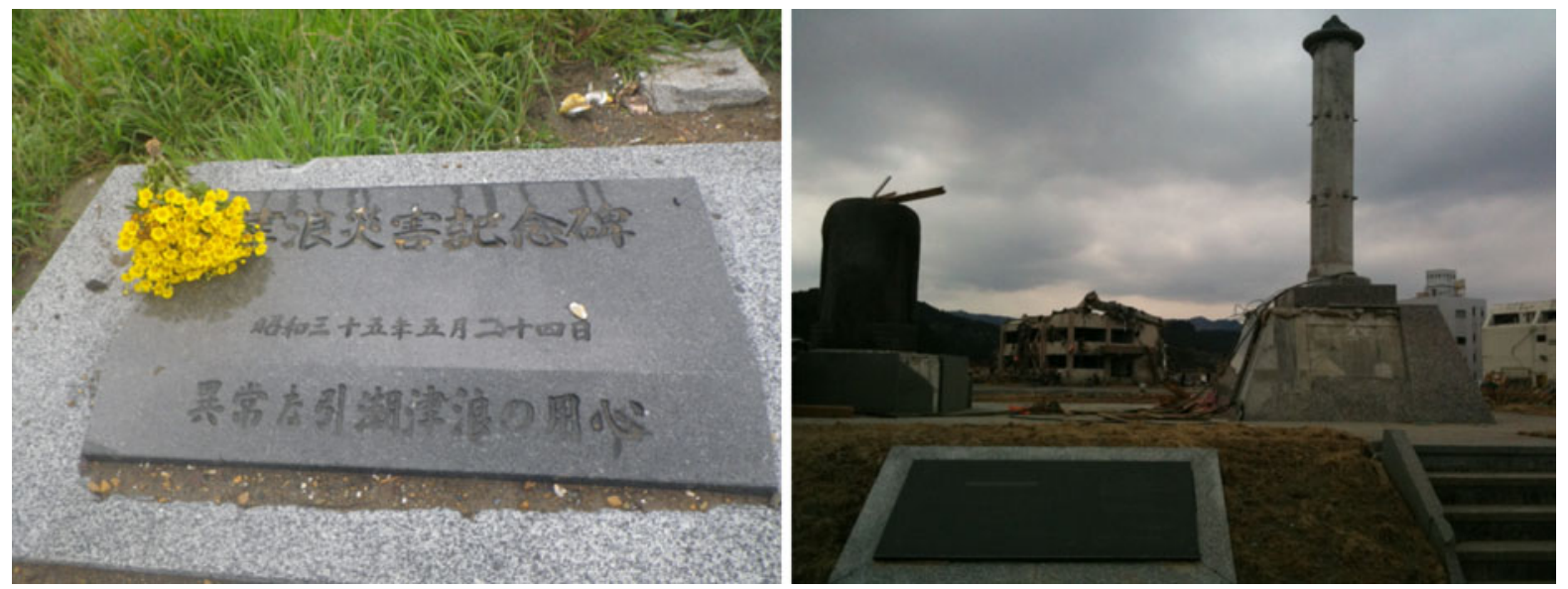

Figure 31

The stone monuments for the 1933 Showa Sanriku tsunami and the 1960 Chile tsunami in Minami-Sanriku town (25/3/2011)
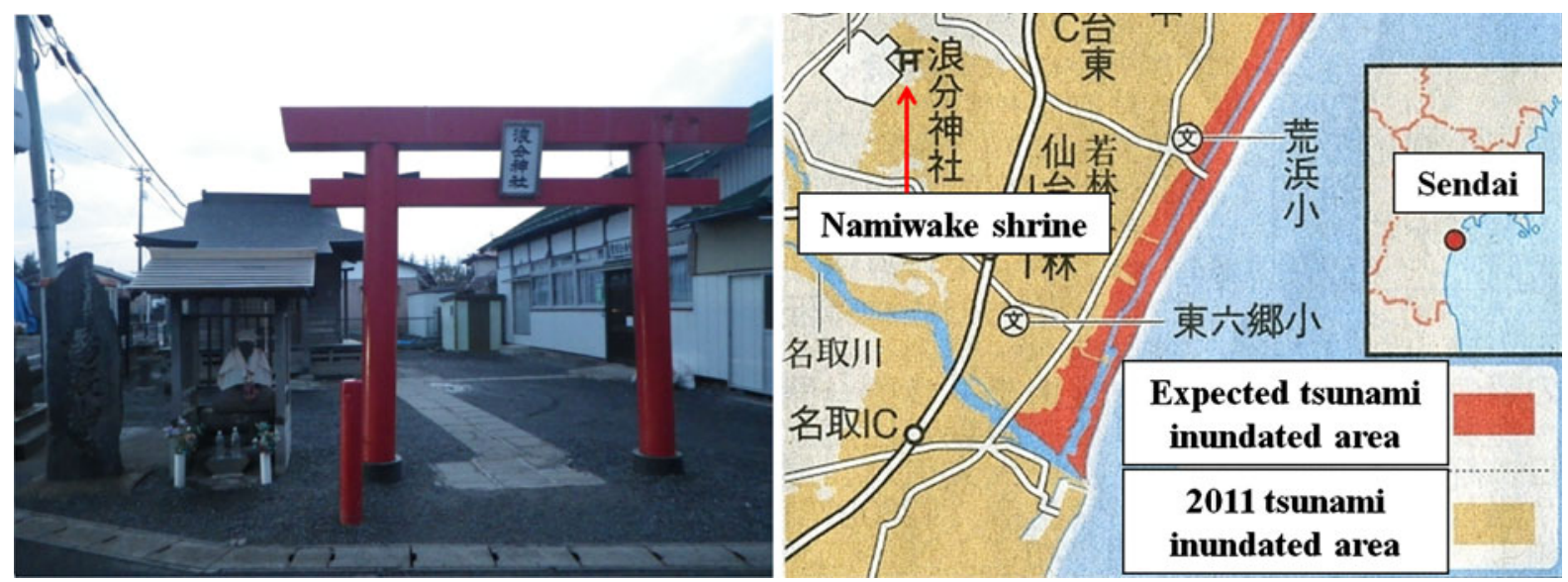

Figure 32

Namiwake Shrine and the inundation area of the 2011 tsunami

evacuate from the tsunami. Therefore, he set fire to his own rice straw and asked people to help him extinguish the fire (in Japanese, "Inamura" means rice straw and "Hi" means fire). All of the town residents came to help him and were saved from the huge tsunami that destroyed the village. Hamaguchi became a hero to the village and spent his own money to construct a seawall. This seawall helped to protect the town from the 1944 Tonankai and 1946 Nankai tsunamis. In memory of this story, the local people, especially the children in the community, help to pile on the earth embankment (Fig. 33, right) and improve their tsunami awareness every year (MATSUSAKA,
2007). Tsunami evacuation drills and education may also increase their skills and knowledge for the next tsunami.

\section{Conclusions, Lessons Learned and Recommendations}

- Many tsunamis have affected the Sanriku coast and Sendai plain in the past, including the 1611 Keicho, 1896 Meiji, 1933 Showa, and 1960 Chile tsunamis. In particular, Sanriku has a ria coastline that is capable of amplifying the height of a 

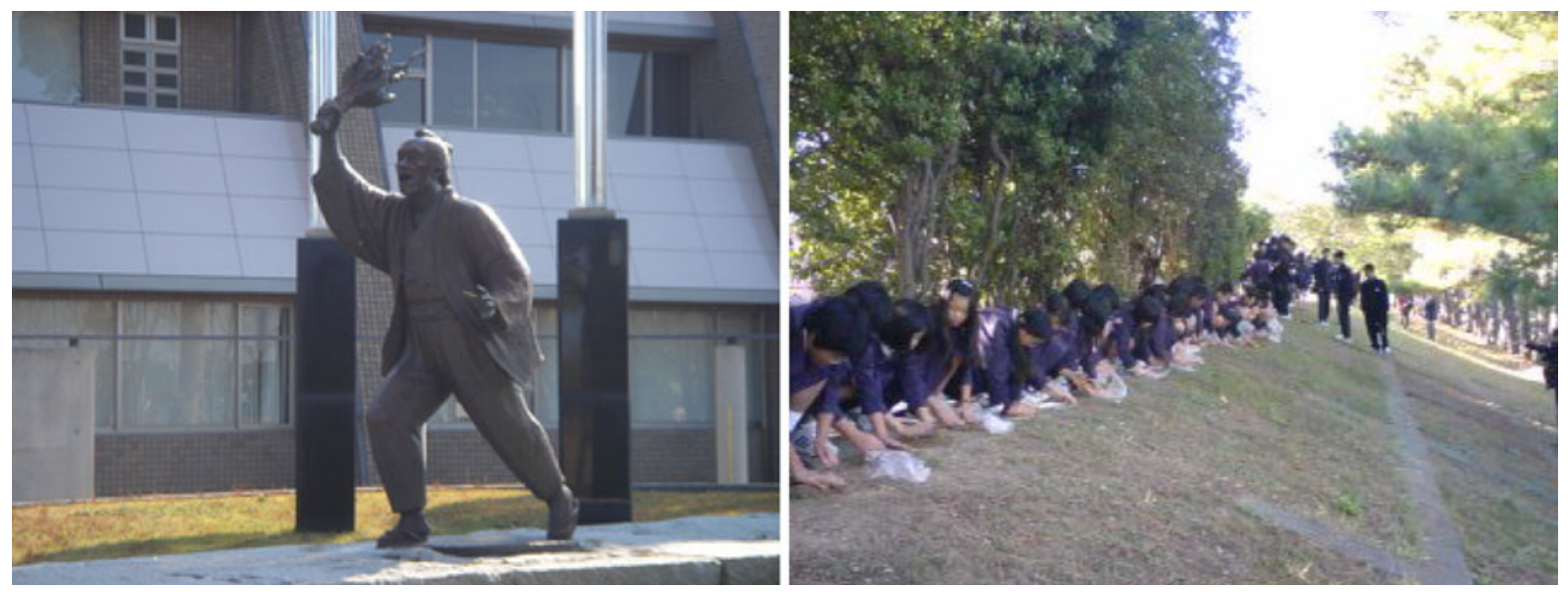

Figure 33

Statue of Hamaguchi Goryo and the activity during the tsunami festival

tsunami. Due to of its ria coastline, Sanriku is one of the areas that has experienced the highest tsunamis in Japanese history. Most of the tsunami countermeasures failed to stop the 2011 Tohoku tsunami because they were not designed to resist an event of this earthquake magnitude. Recent technology has made it possible to build massive structures that could fully protect against 500-1,000year return-period tsunamis; however, these structures are impractical when budget and time are considered. Nevertheless, the scale of damage and loss can be reduced by enacting proper structural design and land-use management policies.

- From the perspective of structural damage, breakwaters and seawalls should have stronger foundations, and there should be more secure connections between neighboring blocks. New designs for stronger and more stable coastal structures should be developed. Tsunami gates and gates in seawalls should be remotely controlled. However, these structures may reduce the tsunami awareness of residents by leading them to believe that the structure fully protects them rather than simply reducing damage; an example of this thinking occurred in Taro town. The scenery should also be considered after the construction of high seawalls; Matsushima town, for example, has one of the best views in the Tohoku area.

- Control forests are not only unable to stop or reduce huge tsunamis such as the 2011 event but may also cause more damage when the trees become floating debris, as observed in Ofunato and Rikuzen-Takata. Because they can only withstand tsunamis with heights up to $5 \mathrm{~m}$, control forests should be planted as a second barrier behind seawalls or at elevations that are higher than the level of the seawalls. Another option is to plant the control forest more deeply in the ground so that their roots can be more connected with the land and increase their strength.

- Wooden structures are good for earthquakes, because of their light weight, but poor at resisting the hydrodynamic force of a tsunami. For areas where the tsunami inundation depth is expected to be low and residential areas are constructed, the first floor of houses should be built as RC structures. The tsunami current velocity is also an important factor in the tsunami force and damage to port facilities including fishing boats. Recent technology, for example video camera analysis, can aid estimation of the velocity. The locations of gasoline and other fuel tanks should be reconsidered; they should be put in safer places where they will not cause fires during a tsunami, as in Kesennuma city.

- The design codes for evacuation buildings should be revised after the examples in Onagawa and some other areas; openings should be considered, and pile foundations should be strengthened. The elevations of railways and roads should be raised so that they can serve as secondary or tertiary tsunami barriers. 
- Evacuation shelters in plains (e.g., the community gym in Rikuzen-Takata city), low-rise buildings (e.g., the disaster prevention building in MinamiSanriku town), and primary schools near the sea or river mouths (e.g., Okawa School in Ishinomaki city) are all examples of failed evacuation shelters. The design and location of tsunami evacuation buildings should be reconsidered. Escape hills can be constructed in plain areas using debris from this tsunami. Evacuation signs should include information not only about tsunami height but also about the height above sea level of each evacuation shelter, evacuation building, and escape hill.

- Although the tsunami was higher along the Sanriku coast, experience and awareness encouraged people to evacuate rapidly. On the other hand, people in the Sendai plain area had less tsunami experience and were slow to evacuate, but the tsunami was lower. These factors may explain why fatalities in the two areas were similar. It is important to remind people in the Sanriku area not to go back once they have evacuated to a safe place. A greater number of high ground areas and evacuation buildings are necessary for the Sendai plain area, and awareness should be encouraged after the 2011 event. Although many structural tsunami defenses can be constructed, evacuation is still the most important and effective method for saving human lives.

- Land use policies for future development should be used to avoid relocation to tsunami-prone areas. Moving to the highland is good for tsunami disaster reduction, but it is also important to evaluate other hazards in sloped areas, for example landslides and floods. Many examples of tsunami warning messages from people in the past are shown on memorial stones, shrines, and temples, especially along the Sanriku coast; these provide information on tsunami heights, arrival times, and inundation limits. These tsunami memorials are important for building awareness and remembering past events, and remain ready for possible future events. Predictions of future population growth are also necessary for designing countermeasures for the 100-1,000-year return-period tsunamis.

- It is important to develop both hard countermeasures, for example breakwaters, seawalls, and tsunami gates, in conjunction with proper land use and soft countermeasures, for example evacuation plans and tsunami awareness education; tsunami education can take the form of memorial parks or hazard maps. These measures prepare towns well for the next tsunami.

\section{Acknowledgments}

We express our deep appreciation to the Tokio Marine and Nichido Fire Insurance Co., Ltd, through the International Research Institute of Disaster Science (IRIDeS) at Tohoku University, the Willis Research Network under the pan Asian/Oceanian tsunami risk modeling and mapping project, and the Ministry of Education, Culture, Sports, Science and Technology (MEXT) project for their financial support. Professor Yalciner acknowledges the Turkish Chamber of Civil Engineers and the TUBITAK 108Y227 Project for their support. We would like to express special thanks to the anonymous reviewers and editor for their comments on improving the quality of the paper.

Open Access This article is distributed under the terms of the Creative Commons Attribution License which permits any use, distribution, and reproduction in any medium, provided the original author(s) and the source are credited.

\section{REFERENCES}

Abe, I. and Imamura, F. (2010), "The 3rd International Tsunami Field Symposium (ITFS), Sanriku field trip guidebook”, 2010, $11 \mathrm{p}$.

Crisis \& Environment Management Policy Institute (CeMI), "Quick questionnaire survey of the Tohoku-Pacific earthquake tsunami", http://www.npo-cemi.com/works/image/2011touhoku/ 110609tsunamisurvey.pdf (in Japanese) (accessed 10 May 2011).

Gokon, H. and Koshimura, S. (2012) "Mapping of building damage of the 2011 Tohoku earthquake and tsunami in Miyagi prefecture," Coastal Engineering Journal, 54(1), 1250006.

Cabinet office, Government of JaPAn (2005), "Guideline for tsunami evacuation building" (in Japanese) http://www.bousai. go.jp/oshirase/h17/tsunami_hinan.html.

IwATE PREFECTURE (2011) Iwate disaster prevention information portal http://www.pref.iwate.jp/ bousai/.

Japan Meteorological Agency (JMA) (2011) "The 2011 off the Pacific coast of Tohoku earthquake", http://www.jma.go.jp/ jma/en/2011_Earthquake.html (accessed 12 June 2011).

KAHOKU NEWSPAPER (2011) Questionnaire to firemen in tsunami affected areas http://www.kahoku.co.jp/spe/spe_sys1062/20111 126_08.htm?style=print (in Japanese). 
KAMAISHI PORT OFFICE (2011), Disaster prevention facilities and safety information http://www.pa.thr.mlit.go.jp/kamaishi/bousai/ index.html.

Koshimura, S., Matsuoka, M. and Kayaba, S. (2009) "Tsunami hazard and structural damage inferred from the numerical model, aerial photos and SAR imageries," in: Proceedings of the 7th International Workshop on Remote Sensing for Post Disaster Response, University of Texas, Texas, United States, 22-23 October 2009, (CD-ROM).

MeiJI UniVERsity, ARChiteCtURAL history AND theORY LABORATORY (2011) Disaster and rehabilitation of village in Sanriku coast from tsunami in 1896, 1933 and $1960 \mathrm{http}: / /$ d.hatena.ne.jp/ meiji-kenchikushi/19530101/p1.

MinAmi-SANRIKU TOWn (2011) "Reconstruction plan after the 2011 Great East Japan tsunami": http://www.town.minamisanriku. miyagi.jp/uploads/ftp_common/sakuteikaigi/20110930soan.pdf.

Ministry of Land, Infrastructure, Transport and Tourism (MLIT) (2011) Investigative commission on tsunami countermeasure in coastal area (in Japanese) http://www.mlit.go.jp/ river/shinngikai_blog/kaigantsunamitaisaku/.

Minoura, K., Imamura, F., Sugawara, D., Kono, Y. and Iwasaki, T. (2001) "The 869 Jogan tsunami deposit and recurrence interval of large-scale tsunami on the Pacific coast of northeast Japan," Journal of Natural Disaster Science, Vol. 23, No. 2, pp. 83-88.

MiYAGI PREFECTURE (2011) Earthquake disaster damage information http://www.pref.miyagi.jp/kikitaisaku/higasinihondaisinsai/higaiz youkyou.htm.

Mori, N., TAKahashi, T. and The 2011 Tohoku Earthquake Tsunami Joint Survey Group (2012) "Nationwide post event survey and analysis of the 2011 Tohoku Earthquake Tsunami," Coastal Engineering Journal, 54(1), 1250001.

MuraI, S. (2011) "Lessons learned from the great east Japan disaster - Conversation from people survived from the tsunami," Kokon-Shoin publishing, 200 p, ISBN-13: 978-4772271103 (in Japanese).

National Police Agency (2011) "Damage condition of the 2011 earthquake off the Pacific coast of Tohoku" http://www.npa.go. jp/archive/keibi/biki/higaijokyo.pdf.

NikKeI NEWSPAPER (2011), Zero damage in Fudai village, Iwate prefecture, apparent effect of the tsunami gate, http://www. nikkei.com/tech/trend/article/g=96958A9C93819499E1E3E2E0 E18DE1E3E2E1E0E2E3E3E2E2E2E2E2E2;p=9694E0E7E2E6 E0E2E3E2E2E0E2E0.

Port and Airport Research Institute (PARI) (2011) Great East Japan Earthquake http://www.pari.go.jp/en/eq2011/.

Santos, A., Koshimura, S., Imamura, F. (2007) "Lessons from the 2004 Indian Ocean Tsunami," Proceedings of the Tohoku Branch of the Japan Society of Civil Engineering, Yamagata, 2 , 3rd March 2007.

Samai, Y., Fuji, Y., Funiwara, O., Kamataki, T., Komatsubara, J., Okamura, Y., Satake, K. and Shishikura, M. (2008) "Marine incursions of the past 1500 years and evidence of tsunamis at
Suijin-numa, a coastal lake facing the Japan Trench," The Holocene 18, 4, 517-528.

SENDAI CITY (2010), Possibility of the Miyagi Sea earthquake http://www.city.sendai.jp/syoubou/bousai/kakuritu/index.html.

Shuto, N. (1985) "Effects and limit of coastal forests against tsunami attack," Proceedings of the Coastal Engineering, JSCE, 32, 465-469 (in Japanese).

Suppasri, A., Koshimura, S. and Imamura, F. (2011) "Developing tsunami fragility curves based on the satellite remote sensing and the numerical modeling of the 2004 Indian Ocean tsunami in Thailand," Natural Hazards and Earth System Sciences, 11, 173-189.

Suppasri, A., Koshimura, S., Imai, K., Mas, E., Gokon, H., Muhari, A. and Imamura, F. (2012a) "Field survey and damage characteristic of the 2011 Tohoku tsunami in Miyagi prefecture," Coastal Engineering Journal, 54(1), 1250005.

Suppasri, A., Mas, E., Koshimura, S., Imai, K., Harada, K. and IMAMURA, F. (2012b) "Developing tsunami fragility curves from the surveyed data of the 2011 Great East Japan tsunami in Sendai and Ishinomaki Plains, Coastal Engineering Journal, 54(1), 1250008.

Suppasri, A., Muhari, A., Ranashinghe, P., Mas, E., Shuto, N., Imamura, F. and Koshimura, S. (2012c) "Damage and reconstruction after the 2004 Indian Ocean tsunami and the 2011 Great East Japan tsunami," Journal of Natural Disaster Science (in press).

Tsunami Engineering Laboratory (TEL), Disaster Control Research Center (DCRC), Tohoku University (2011) "Inspection of structural damage in the affected areas of the 2011 Tohoku Tsunami”, http://www.tsunami.civil.tohoku.ac.jp/tohoku 2011/mapping_damage.html (accessed 27 May 2011).

Token C. E. E. Consultants Co., Ltd. (2011), Technology topics http://www.tokencon.co.jp/technology/topics/akg7b200000024ca. html.

WAKAYAMA BROADCASt (2009), Hirogawa town http://wbs-waka. sblo.jp/article/25970894.html.

Yalciner A. C., Suppasri A., Mas E., Kalligeris, N., Necmioglu, O., Imamura, F., Ozer, C., Zaytsev, A., Ozel, N. M. and SynOLAKIs, C. (2012) "Field survey on the coastal impacts of March 11, 2011 great east Japan tsunami", Pure and Applied Geophysics (This volume).

YAMASHita, F. (2008a), Tsunami and disaster prevention-Sanriku tsunami, Kokon-Shoin publishing, 158 p, ISBN-13: 9784772241175 (in Japanese).

YAMASHITA, F. (2008b) "Tsunami tendenko: History of recent tsunamis in Japan," Shinnihon publishing, 235 p, ISBN978-4406-05114-9 (in Japanese).

YOMIURI NEWSPAPER (2011a) "Saving life of firemen when closing water gate during tsunami" http://www.yomiuri.co.jp/feature/ 20110316-866918/news/20111030-OYT1T00853.htm.

YOMIURI NEWSPAPER (2011b) "Tsunami reduction effect by disaster prevention forests" http://www.yomiuri.co.jp/feature/20110316866918/news/20111005-OYT1T01498.htm. 